علاقة وصف ابعاد الحالة البدنيه والاتجاه نحو المنافس ببعض البـ البـان

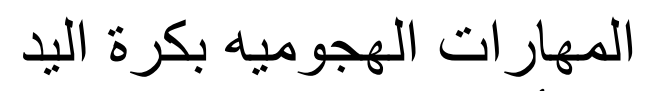

أ.م.د. أحمد اجود كاظم أ.م.د. ساهرة رزاق كاظم م.د اقبال عبد الحسين ليذ

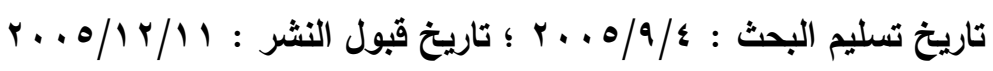

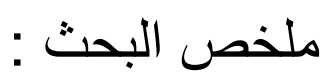

تعد كرة اليد من الألعاب التتافسيه التي تظهر فيها المواجهه المباشرة بين اللاعبين وان من العوامل التي تميز لاعب المنتخب الرياضي عن الرياضي الاقل نجاحا هو تماسكه اثثاء تتفيذ المهارة

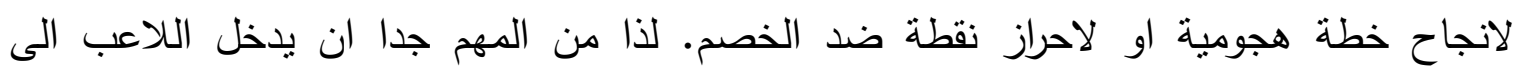

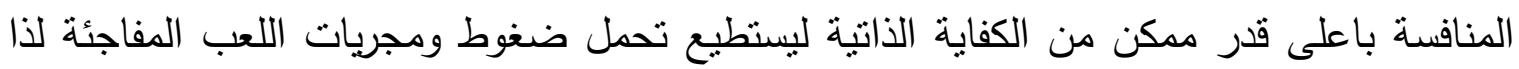

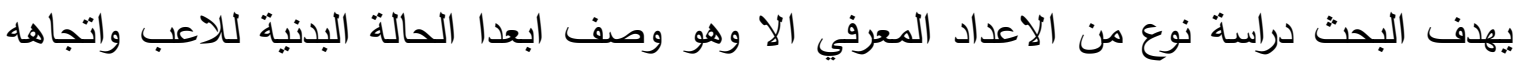
نحو المنافسة في بعض المهارات الهجومية بكرة اليد. لق افترض الباحثون - وجود علاقـة ارتبـاط بين ابعـاد وصف الحالـة البدنيـة والاتجـاه نحو المنـافس يبعض المهارات الهجومية بكرة اليد.

- وجود علاقة ارتباط بين ابعاد وصف الحالة البدنية والاتجاه نحو الدنافس للاعبة كرة البد. - - تاثير ابعاد وصف الحالة البدنية والاتجاه نحو المنافس لاى لاعبة كرة اليد.

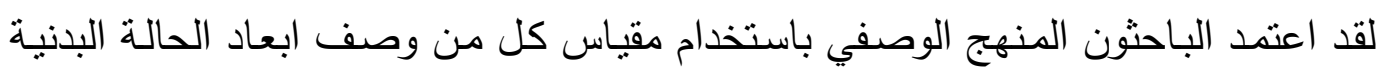

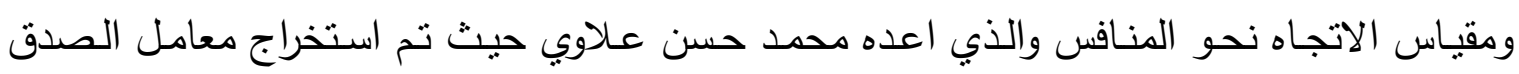

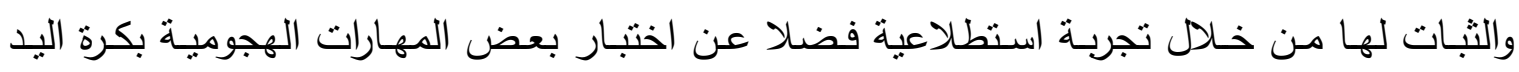
(مناولة سوطية-طبطبة-تهديف).

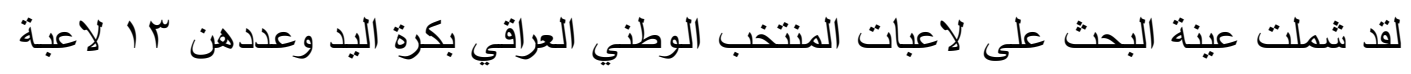

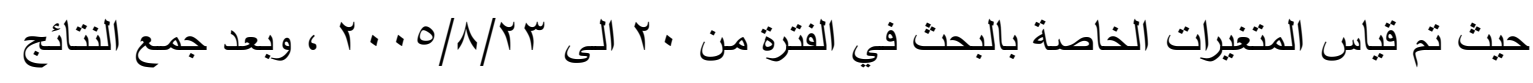

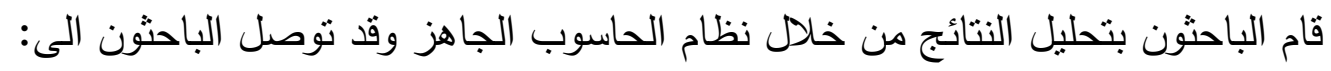
1. وجود علاقة ارتباط قوية بين ابعاد وصف الحالة البدنية (قوة-سرعة-مطاولة-رشاقة-مرونة) والاتجاه نحو المنافس ببعض المهارات الهجومية (مناولة سوطية-تهديف).

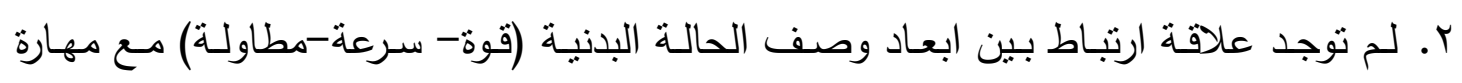
الطبطبة. 


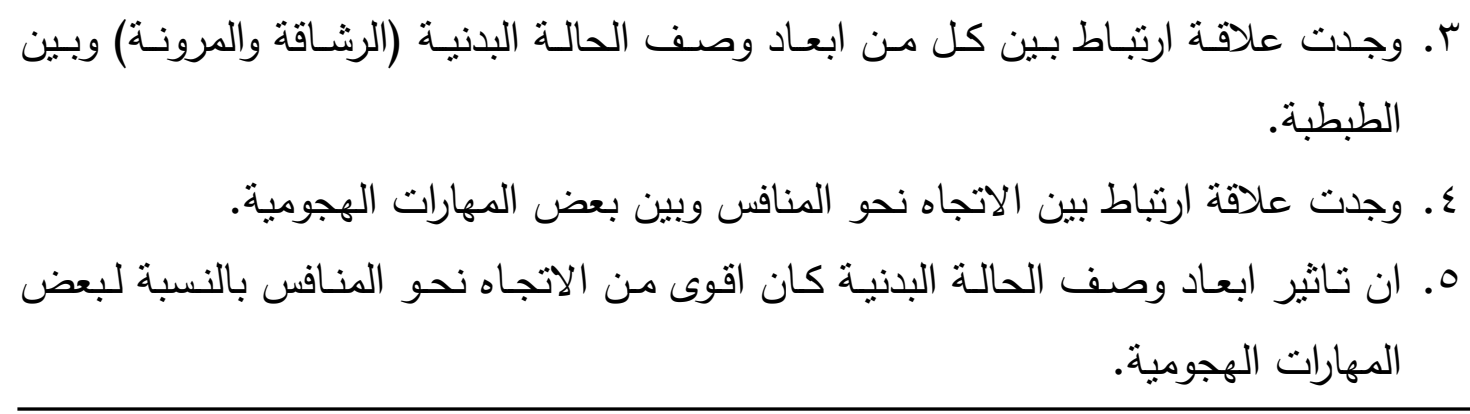

\title{
Correlation of Physical Case Description and Attitude towards Apposing Player with Some Attacking Skills in Handball.
}

\author{
Assist. Prof. Dr Ahmed Gwad \\ Assist. Prof. Dr Sahira Razak Kadhm \\ Lecturer Aqbal Abd Al Hussain
}

\section{Abstract:}

Handball is one of competitory games that implies direct meeting face to face between players. Some factors that distinguish a sport teemplayer from a less successful one is self- control during performing the skill to let an attacking plan be successful or to gain a score against the apposing player.

So, it is very important for the player to join the competition with utmost possible self- efficiency in order to endure sudden pressure and incident through the game. Therefore the research aims at some sort of acknowledge preparation that is description of physical case dimension of the player and attitude to words competition with some attacking skills in handball.

Research hypothesis:

1. There is correlation between physical case description dimensions and attitude to words apposing player with some attacking skills in handball.

2. There is correlation between physical case description and attitude to words apposing player.

3. Effect of physical case description dimension and attitude towards the apposing player of a handball player.

The researchers adopted the descriptive methods through using both measures of physical case description dimensions and attitude towards apposing player, prepared by M. H. Allawi, where coefficient of validity and reliability were extracted through survey experiment in addition to testing of some attacking skills in handball ( whip pass, tapping, targeting ). The research simple comprised thirteen Iraqi national 
females' handball team players. Measure of certain variables of this research was done on Aug.20-23rd 2005. After collecting the results, the researchers analyzed through APSS and got the conclusions. Some of these conclusions are:-

1. There is a strong correlation between physical case description dimension (strength, speed, endurance, agility, flexibility) and attitude to words apposing player with some attacking skills (Whip pass, targeting).

2. There is no correlation between physical case description dimensions (strength, speed, endurance) with tapping skills.

3. There is correlation between physical case description dimension (agility, flexibility) and a tapping.

4. There is correlation between attitude to words apposing player and some attacking skills.

5. The effect of physical case description dimension of female players was stronger than attitude to words apposing player in some attacking skills.

\section{ا ـ المقدمة و أهمية البحث:}

تزخر الأنشطة الرياضية بما لا يعد من المواقف التنافسية التي تؤثر بشكل كبير على

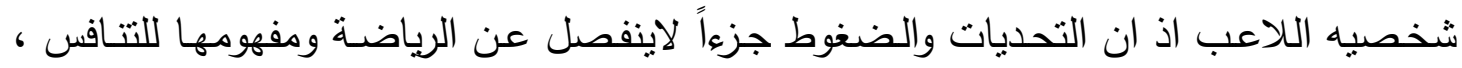
وكرة اليد واحده من هذه الرياضيات التتافسي والتي يواجه فيها اللاعب تحديات وضغوط سواء لاء لاءياء أثناء المنافسة او قبلها أثناء التنريب ، فكرة اليد بمفهوم اللاعب ليست فاطيات فاصرة على التهديف وإنما

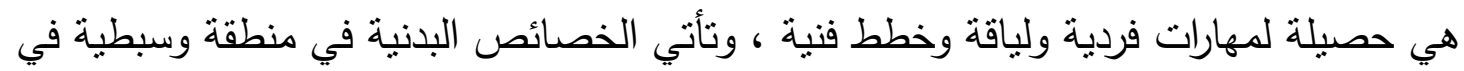
الهرم الذب افترضه (كراتي)) حيث يثير الى ان سمات القدرة الجسمية مثل الخصائص البدنيه

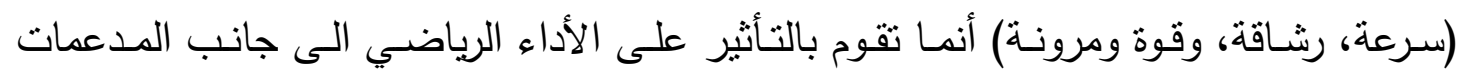

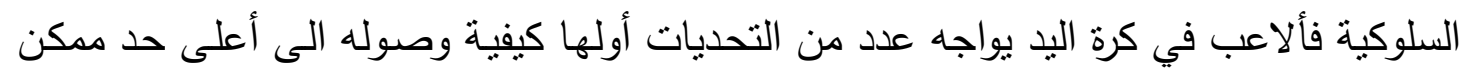
من القدرة الجسميه بإبعادها ، للإحساس بذاته البدنيه التي تولد لايهه القدرة على الأداء أثناء

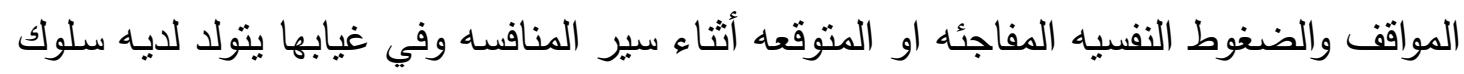

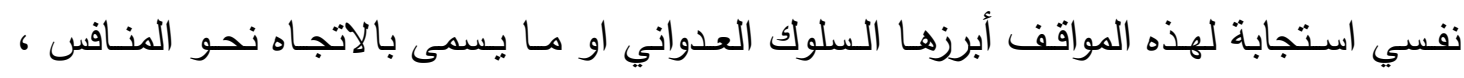

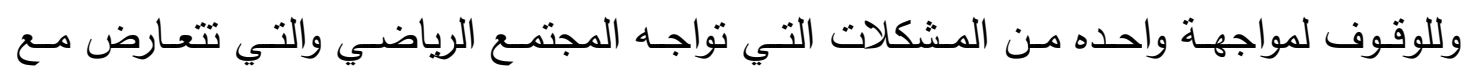

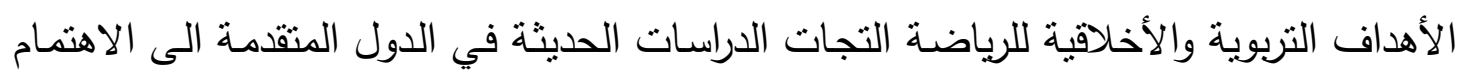

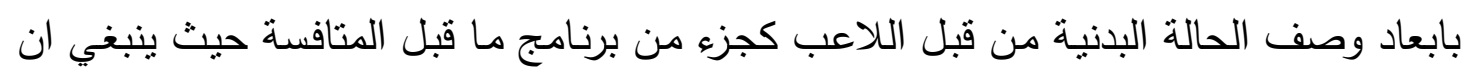

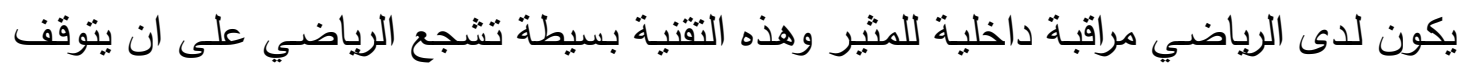

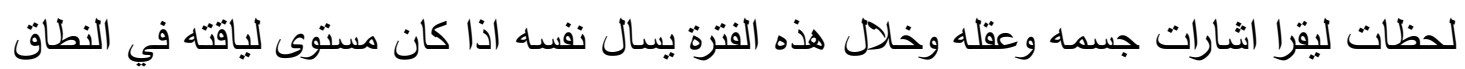


المثالي وهل يحتاج الى بعض الاساليب من تغتير جاءت أهية البحث في دراسةعلاقة أبعاد

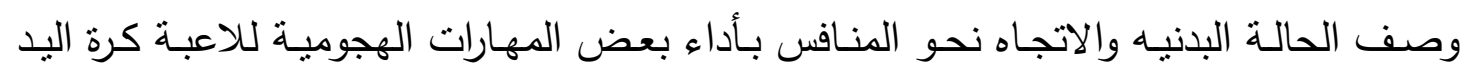

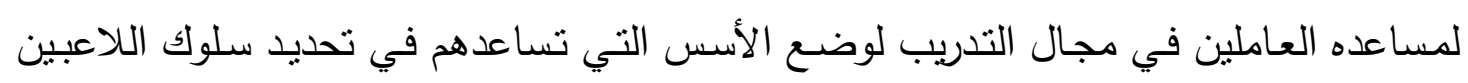
أثناء المنافسه

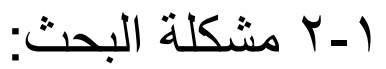

تعد كرة اليد من الرياضات التتافسية والتي فيها الاحتكاك بصورة واضحة بين اللاعبين

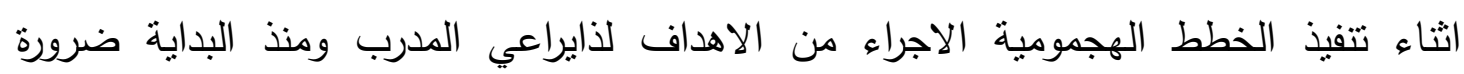
الاهتمام بالقدرات البدنية والمهاريه للاعب حيث يثير الابحاث " من العوامل التي تميز لاعب الاهب

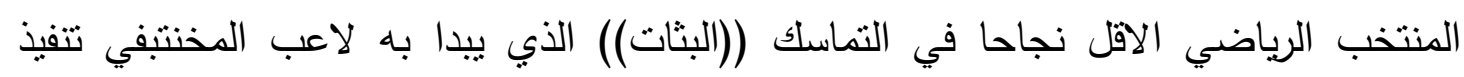

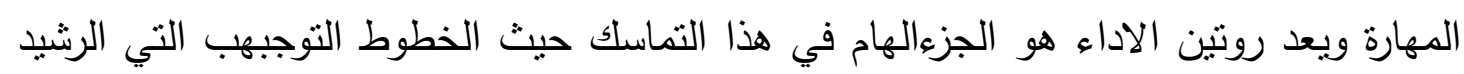

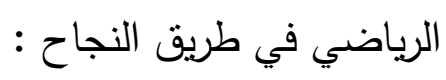

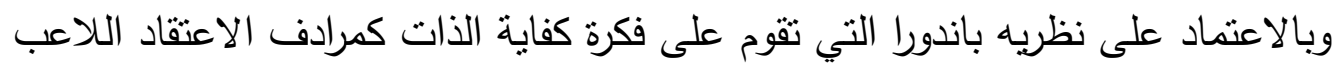

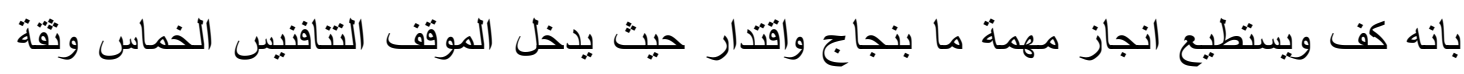
جاءت مشكله البحث في دراسة المنافسة من خلال ربطة بمتغيرين اخرين هو الاتجاه نحو

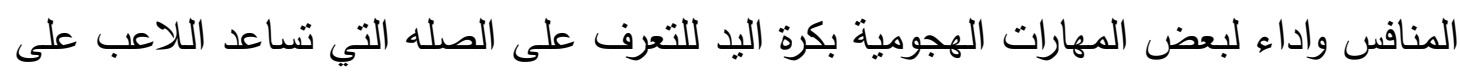
ايجاد النطور المتكامل اللاعبه والذي يرتبط بفهم طبيعة المنافسة والجوانب النفسية والبدنبة

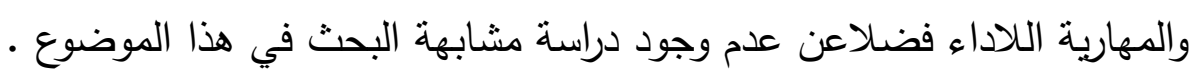

$$
\begin{aligned}
& \text { ا _ اهداف البحث } \\
& \text { يهدف البحث الى التعرف على الهد }
\end{aligned}
$$

ا ـ علاقة أبعاد وصف الحالة البدنيه ببعض المهارات الهجوميه بكرة اليد للاعبات المنتخب

$$
\text { الوطني العراقي }
$$

r. علاقة الاتجاه نحو المنافس ببعض المهارات الهجوميه بكرة اليد للاعبات المنتخب الوطني

العراقي

r. علاقة ابعاد وصف الحالة البدنيه بالاتجاه نحو المنافس لدى اللاعبه كرة اليد 


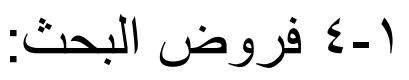

ا ـ وجود علاقة ارتباط بين أبعاد وصف الحالة البدنيه والاتجاه نحو المنافس ببعض المهارات

الهجومية بكرة اليد للاعبات المنتخب الوطني العراقي لوبي

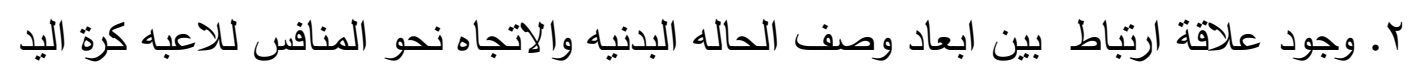

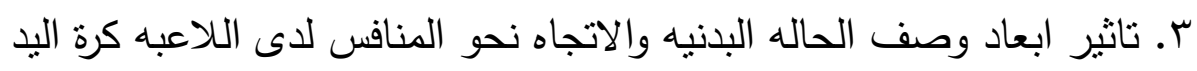

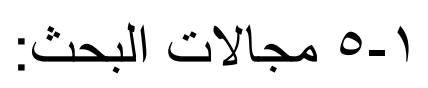

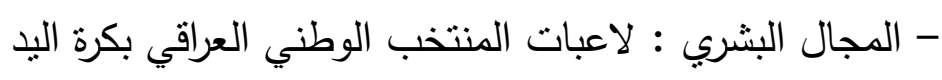

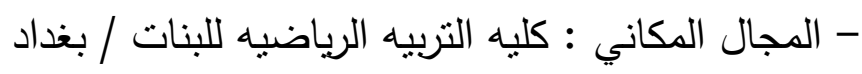

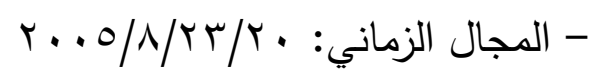

ا -7 تحديد المصطلحات

- الاتجاه نحو المنافس : "سلوك موجه ومقصود ضد فرد أخر بهدف الإيذاء او ايقاع الضرر

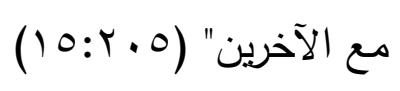

- الحاله البدنيه : "قدرة الاعب على تقدير مايمتكله من ابعاد بدينه تمكلنه من خلق ثقة من تحقيق العمل الحركي او الواجب الحركي المراد منه"

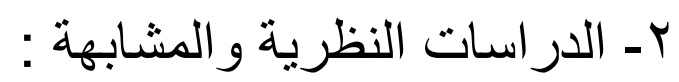

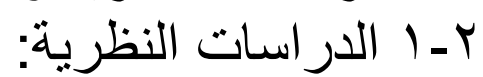
Y - ا - ا الاهية الاتجاه نحو المنافسة:

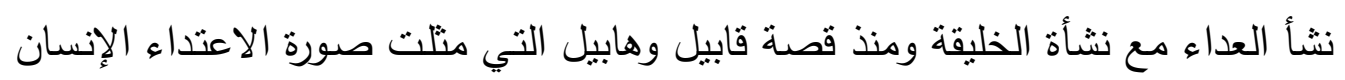
على أخيه الإنسان وحتى يومنا هذا وهو يتمثل بالاعتداء الفردي او الجماعي ويخذ إنتكال

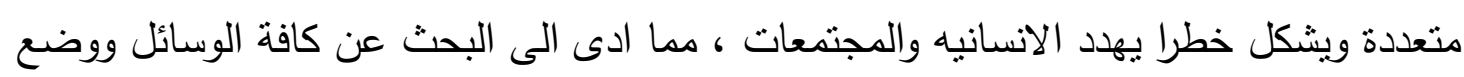

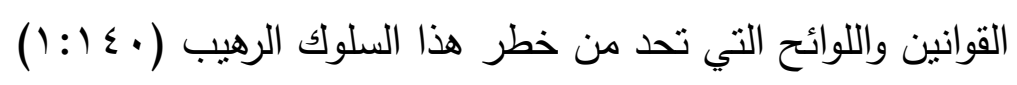

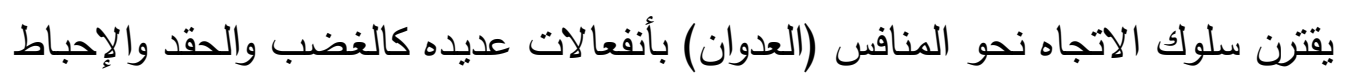

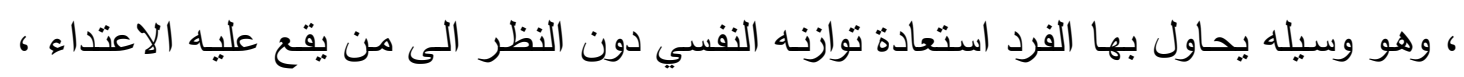

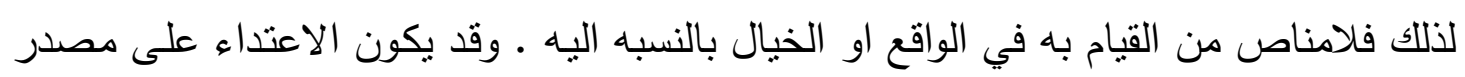

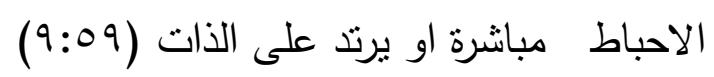

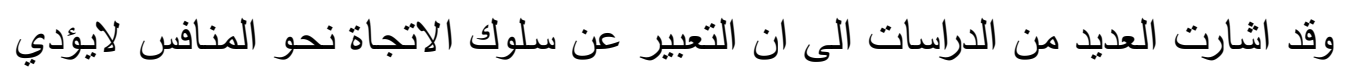

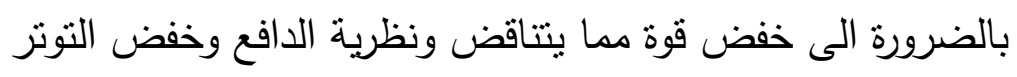




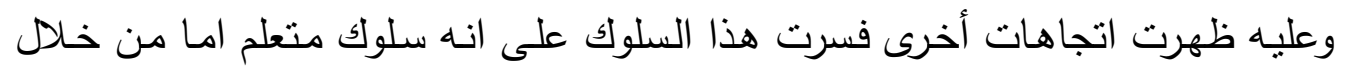

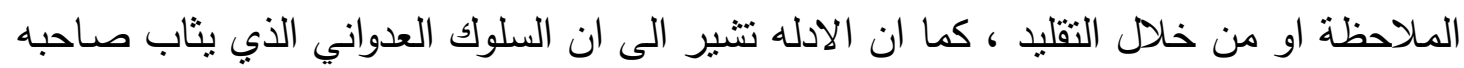

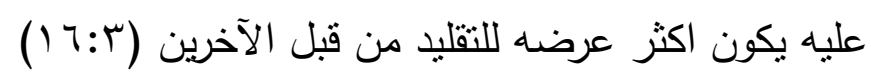

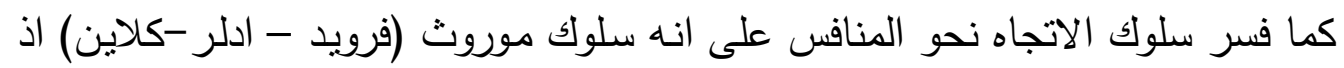

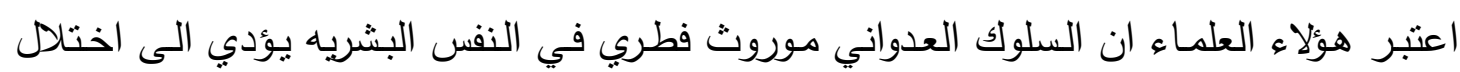
كيانه وتدهوره وعليه فهو سلوك غريزي (19 (: 1)

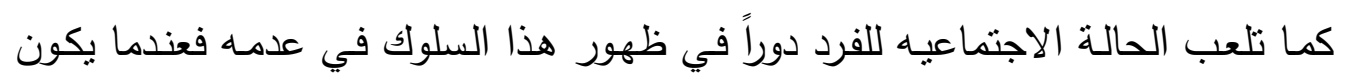
الفرد عضوا في مجموعه متماسكه فان أي اعتداء عليه يقوم بدفعه الى الاستتاره والاستجابه

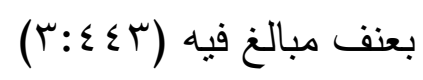

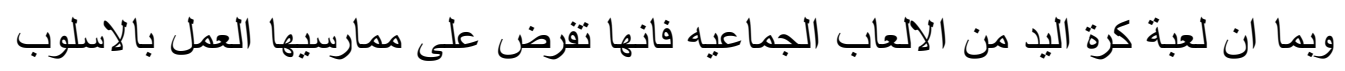

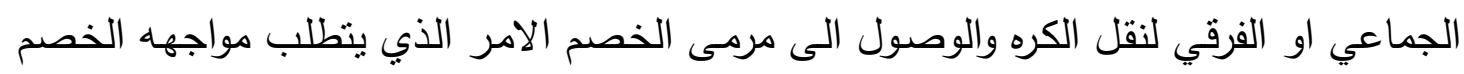

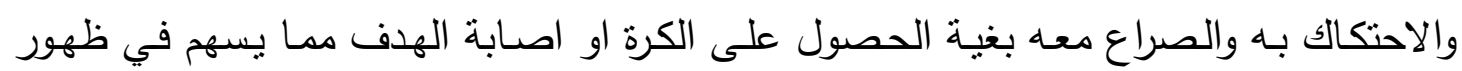

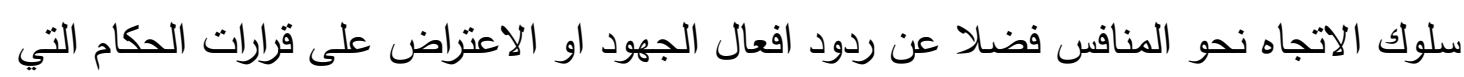
تتسبب بشكل او بأخر بالتصرف بعدائية من قبل اللاعبين

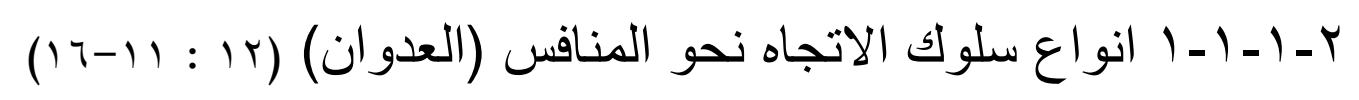
حاول الباحثون النظر الى سلوك الاتجاه نحو المنافس من خلال الهدف من هذا السلوك الهو الهو

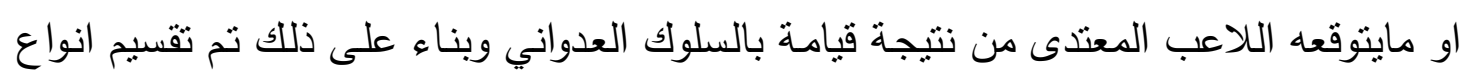

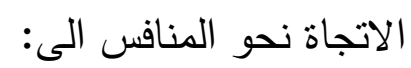
ا. العدوان العدائي : وهو محاولة اللاعب اصـابة اللاعب المنافس لاهداف الآم والاذى مثل

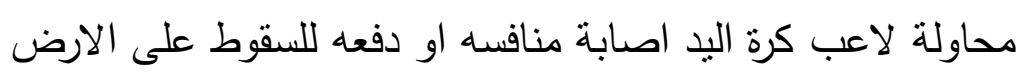

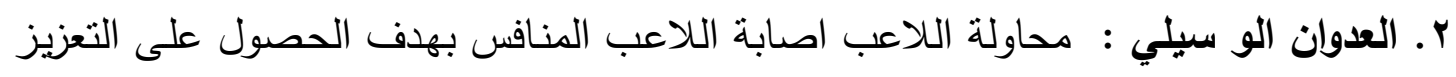

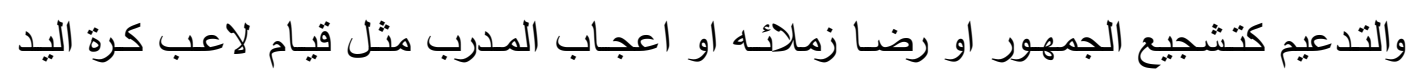

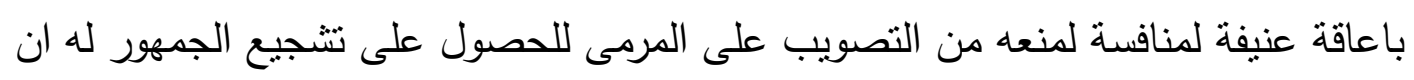

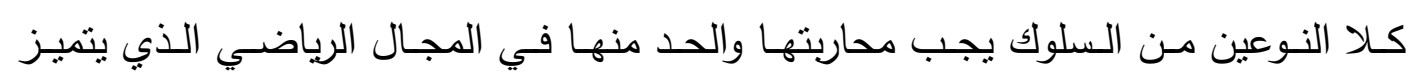
بالمنافسه الشريفه واللعب النظيف في ظل قوانين ثابته ومعروفه تدين هذان النوعين من

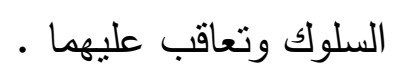
r. السلوك الجـازم: نوع من السلوك البدني او اللفظي يقوم بـه اللاعب اثثاء المنافسه والذي

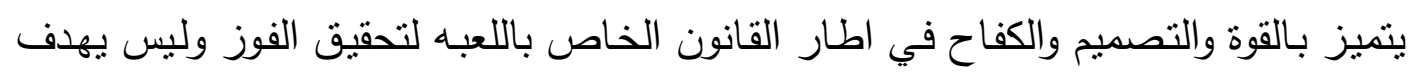

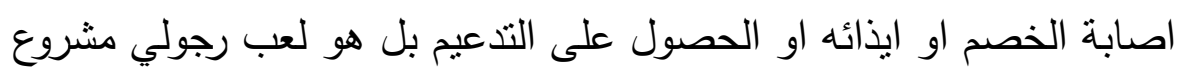




\section{وصف الحالة البدنيه :}

ان وصف الحالة البدنيه هو التعبير الذاتي من قبل اللاعب حول مايمتلكه من الصفات

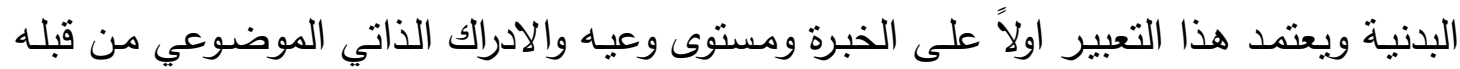

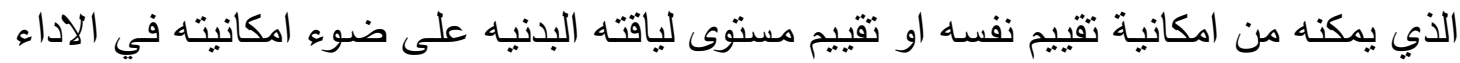

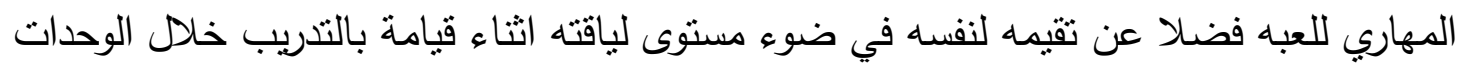

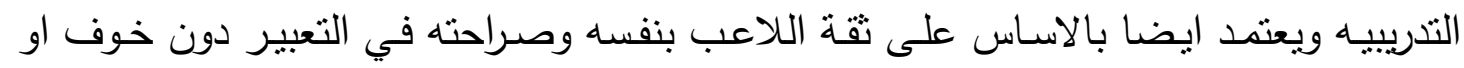

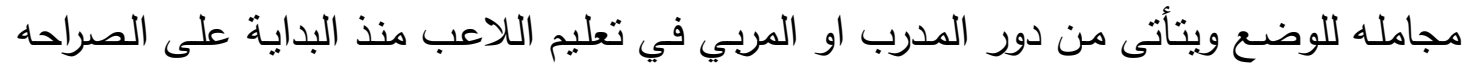

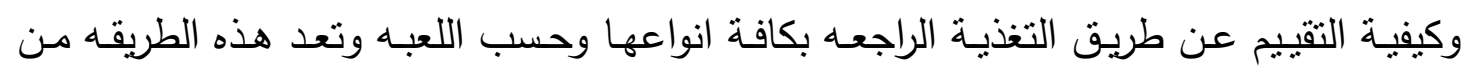

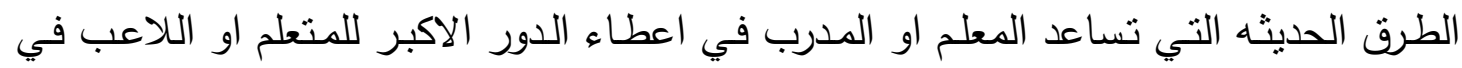

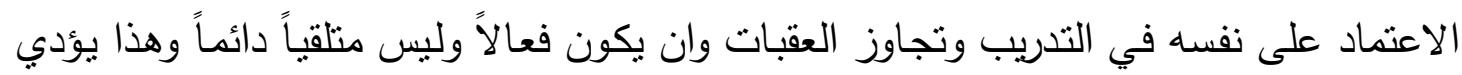

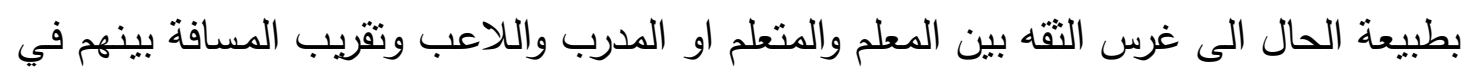

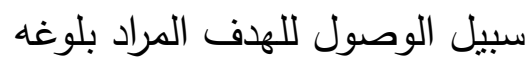

$$
\text { r بـ اجر اءات البحث: }
$$

استخدم الباحثون المنهج الوصفي لملائمته وطبيعة البحث

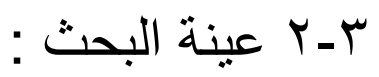

تمنلت عينة البحث بلاعبات المنتخب الوطني العراقي في كرة اليد للنساء وبلغ عددهن

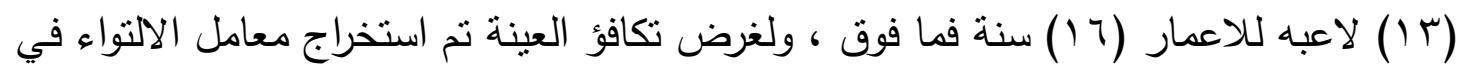

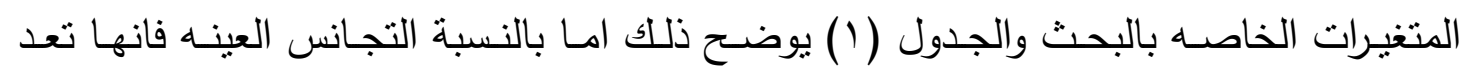

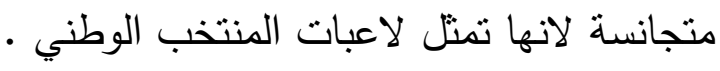

\begin{tabular}{|c|c|c|c|c|}
\hline التقلطح & الانحراف & الوسيط & \multicolumn{2}{|c|}{ المتغيرات } \\
\hline$\cdot, \leqslant 9$ & I, IV & $19, \cdot 177$ & قوة عضليه & \multirow{5}{*}{ ابعاد وصف الحاله } \\
\hline$\cdot, \cdot r \varepsilon$ & $r, Y \vee \wedge$ & $1 \wedge, \vee>9$ & التحمل & \\
\hline$\cdot, 194$ & سז, 1 & $1 \Lambda, O H \wedge$ & السرعة & \\
\hline $7,9 \mu v$ & $r, O Y \leq$ & $I V, r \wedge \varepsilon$ & مرونه & \\
\hline$-\cdot, r \vee r$ & r, rVo & 11, 10r & رشاقة & \\
\hline $1, \cdot \varepsilon \wedge$ & $9, V Y \wedge$ & V1, 10r & \multicolumn{2}{|c|}{ الاتجاه نحو المنافس } \\
\hline$-1, \leqslant 91$ & $r, I \leqslant r$ & YI, rᄉE & \multicolumn{2}{|c|}{ المناوله السوطيه } \\
\hline$-\cdot, 711$ & $1, \ldots$ & $r \varepsilon, \ldots$ & \multicolumn{2}{|r|}{ الطبطبه } \\
\hline $1, \cdot 1$ & $1, \wedge \leq 7$ & $r_{1, \cdot V r}$ & \multicolumn{2}{|r|}{ التصويب } \\
\hline
\end{tabular}

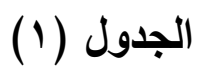

يبين تكافؤ العينة في متغيرات البحث 


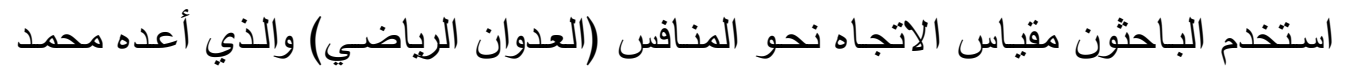

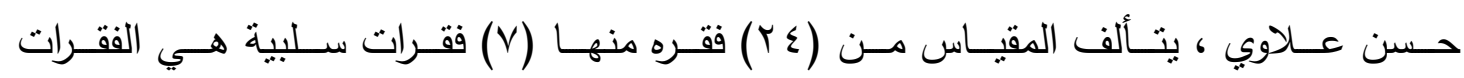

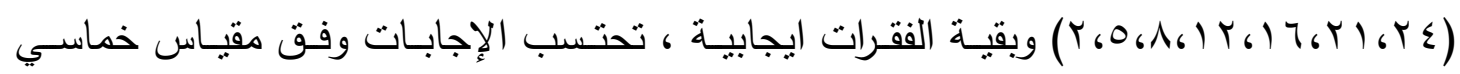

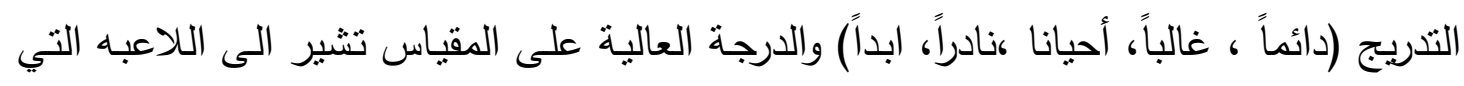
يغلب عليها طابع الخشونة والعدوان

\section{r-r-r مقياس وصف الحاله البدنيه :}

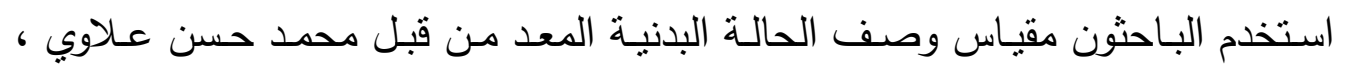

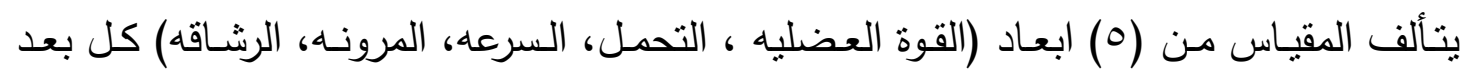

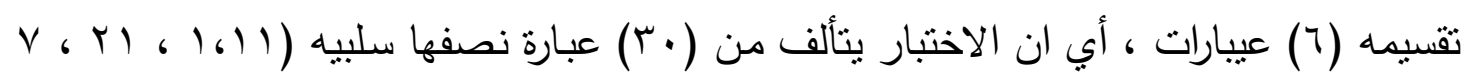

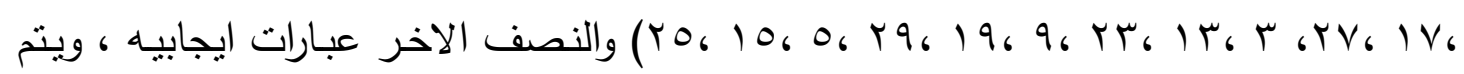

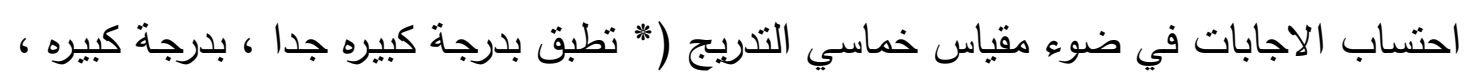

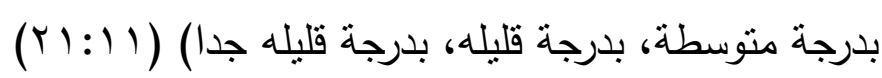

$$
\text { r-r-r الاختبار ات المهاريه بكرة اليد : (؟:؟r) }
$$

لقياس مستوى الاداء المهاري بكرة اليد نم اعتماد الاختبارات التاليه

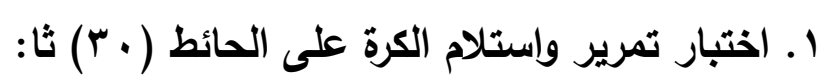

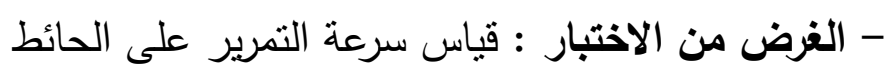

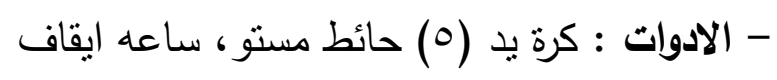
- وضـع الاداء : تقف المختبره على بعد (" م) مـن الحائط وتقوم بتمرير الكرة الى الحسائط واستمرار التمرير لاكثر عدد ممكن في الزمن المحدد

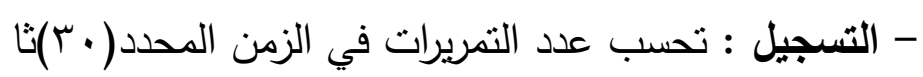

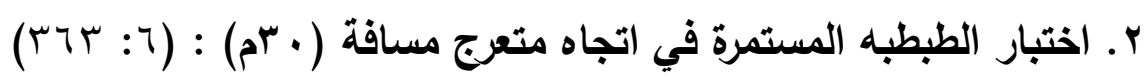
- الغرض من الاختبار : قياس مستوى مهارة الطبطبه

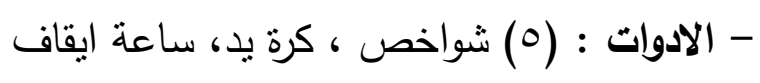

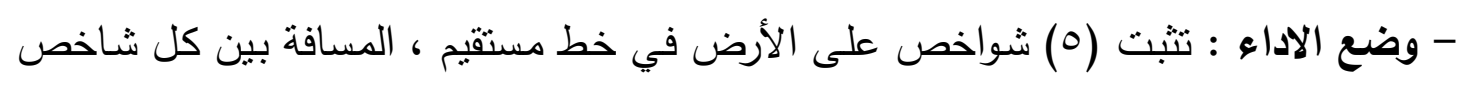

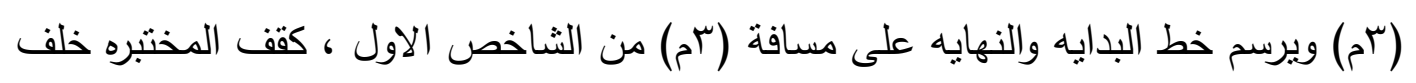


خط البداية وعند الإثارة تقوم بطبطبة الكرة مع الجري على شكل متعرج بين الثواخص ذهابا وايابا حتى تعبر خط النهايه - التسجيل: يحسب الزمن المسجل ذهابـاً واياباً من لحظه البدء حتى تخطي المختبره لخط النهاية

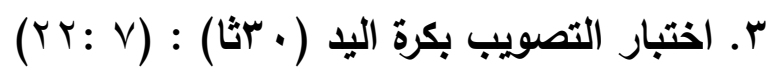
- الغرض من الاختبار : قياس دقة النصويب

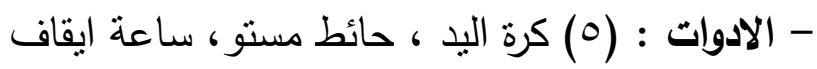

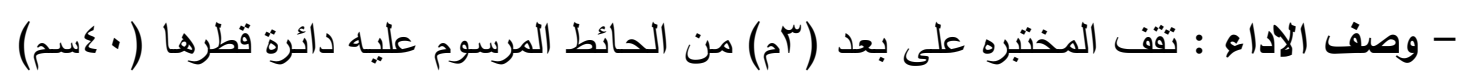

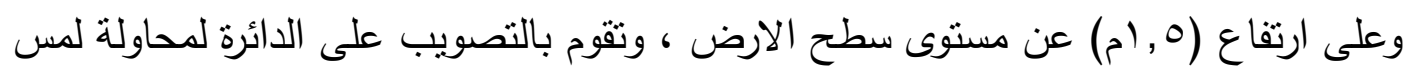
منتصفها وذللك في زمن قدرة (· مثان) - التسجيل : تحتسب عدد المرات الصحيحه في التصويب في منتصف الدائرة في الزمن

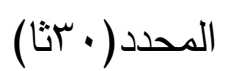

$$
\text { ب-ـ الاسس العلمية للاختبار ات : }
$$

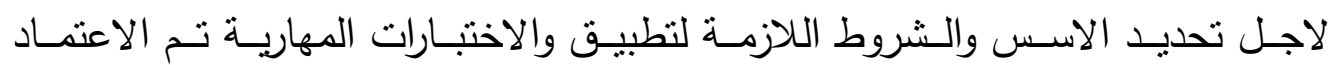

الاجراءات التاليه

1. للتحقيق من صدق الدقاييس والاختبارات التي تم استخدامها ، تم عرضـها على الخبراء

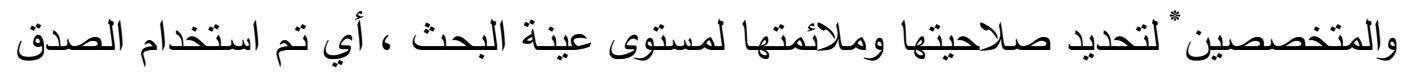

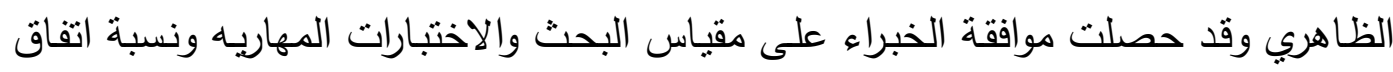

$\%$ \% \% .

r. فيما يتعلق بالثبات والذي يشير الى درجة استقرار الاختبار والتتاسق بين اجزائه فقد تم ايجاد

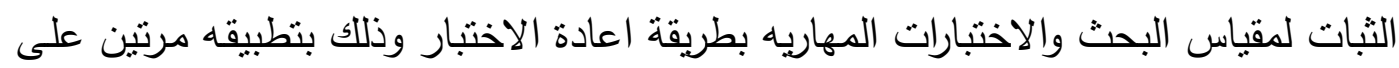

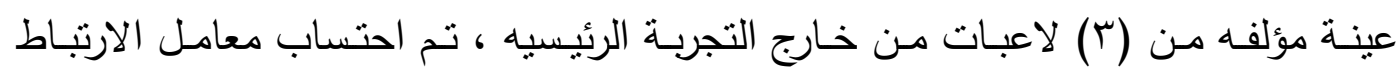

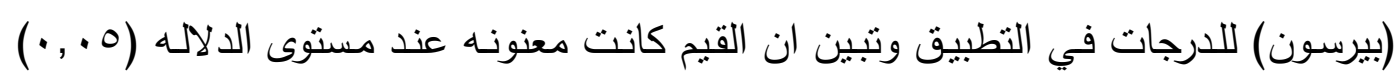

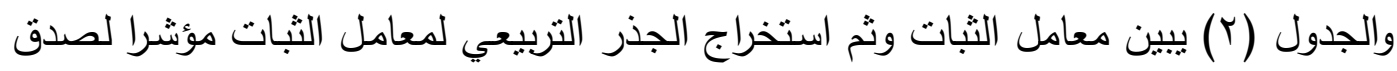

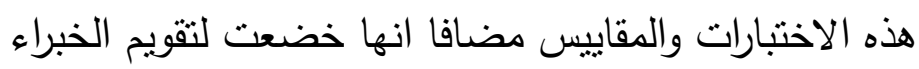




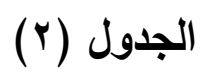

يبين معامل الصدق والثبات لمتغيرات البحث

\begin{tabular}{|c|c|c|c|}
\hline الانحراف & الوسيط & \multicolumn{2}{|c|}{ المتغيرات } \\
\hline$\cdot, \Lambda T$ & $\cdot, V T$ & قوة عضليه & \multirow{5}{*}{ البعاد وصف الحاله } \\
\hline$\cdot, \wedge 9$ & $\cdot, \vee \vee q$ & | التحمل & \\
\hline$\cdot, 91$ & $\cdot, 9 V$ & | السرعة & \\
\hline$\cdot, 90$ & $\cdot, 9$ & | مرونه & \\
\hline$\cdot, \wedge 0$ & $\cdot, V Y$ & | & \\
\hline$\cdot, 9 \leq$ & $\cdot, \wedge \wedge$ & \multicolumn{2}{|c|}{ الاتجاه نحو المنافس } \\
\hline$\cdot, \wedge 0$ & $\cdot, V r$ & \multicolumn{2}{|c|}{ المناوله السوطيه } \\
\hline$\cdot, 9 r$ & $\cdot, 10$ & & الطبطبه \\
\hline$\cdot, 91$ & $\cdot, 97$ & & التصويب \\
\hline
\end{tabular}

ع - عرض النتائج ومناقنتها :

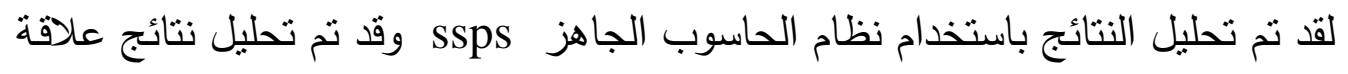
ابعاد وصف الحاله البدنيه والاتجاه نحو المنافس ببعض المهارات الهجوميه بكرة اليد الجدول (r)

يبين معامل الارتباط بين وصف الحاله البلنيه والاتجاه نحو المنافس للاعبات ويعض مهارات كرة اليل

\begin{tabular}{|c|c|c|c|c|c|c|c|c|c|}
\hline تصويب & طبطبه & السوطيه & الاتجاه نحو & رشاقه & مرونة & سرعة & التحمل & قضليه & وصف الحالة \\
\hline $\begin{array}{c}* \cdot, \text { ATr } \\
*\end{array}$ & $-\cdot, r \leqslant 1$ & $\begin{array}{c}* \cdot, \wedge \varepsilon \Lambda \\
*\end{array}$ & $\begin{array}{c}* \cdot, \text {, } 0 \mathrm{~V} \\
*\end{array}$ & $\begin{array}{c}* \cdot, 9 \cdot 1 \\
*\end{array}$ & $\cdot, \varepsilon r \leqslant$ & $\begin{array}{c}* \cdot, \wedge Y \Gamma \\
*\end{array}$ & $\begin{array}{c}* \cdot, \wedge \wedge q \\
*\end{array}$ & & قوة عضليه \\
\hline $\begin{array}{c}* \cdot, \wedge 97 \\
*\end{array}$ & דצז,.-- & $\begin{array}{c}* \cdot, q \cdot \vee \\
*\end{array}$ & $\begin{array}{c}* \cdot, 911 \\
*\end{array}$ & $\begin{array}{c}*, 917 \\
*\end{array}$ & $\cdot, \sum \wedge 9$ & $\begin{array}{c}*, 90 r \\
*\end{array}$ & & & التحمل \\
\hline $\begin{array}{c}*, \wedge \top \wedge \\
*\end{array}$ & $-\cdot, \varepsilon r q$ & $\begin{array}{l}\cdot, \wedge \wedge T \\
* *\end{array}$ & $\begin{array}{c}* \cdot, 91 \leq \\
*\end{array}$ & $\begin{array}{c}*, 9 \leq \wedge \\
*\end{array}$ & ., orq & & & & سرعة \\
\hline $\begin{array}{c}*, V \leq r \\
*\end{array}$ & $\begin{array}{c}*, V T r \\
*\end{array}$ & $* 107 \varepsilon$ & $* ., O N Y$ & $* .07$. & & & & & مرونة \\
\hline $\begin{array}{c}*, \text {, } \\
* \% r \\
*\end{array}$ & $* ., 071$ & $\begin{array}{c}*, \wedge \wedge \wedge \\
*\end{array}$ & $\begin{array}{c}*, \wedge \leq 7 \\
*\end{array}$ & & & & & & رشاقه \\
\hline $\begin{array}{c}*, 9 Y V \\
*\end{array}$ & $\cdot, 19 V$ & $\begin{array}{c}*, \wedge \vee \vee \\
*\end{array}$ & & & & & & & الاتجاه نحو \\
\hline
\end{tabular}




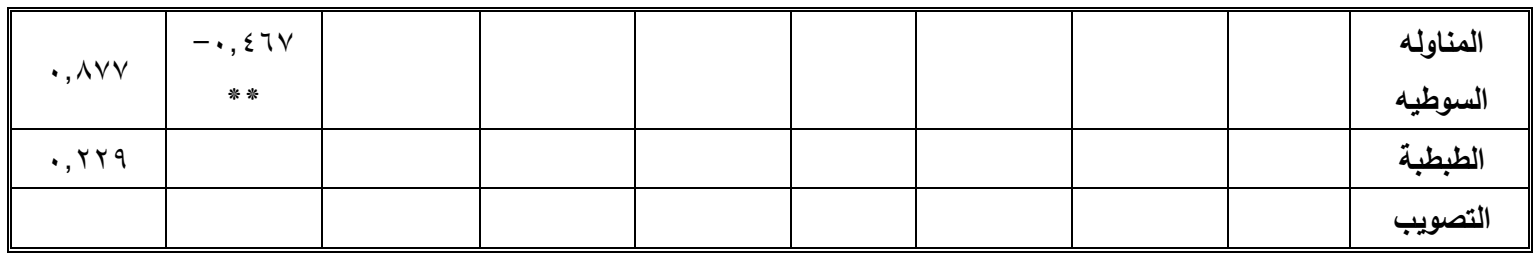

لتحقيق الفرضية الاولى يبين الجدول (r) ان هنالك علاقه ارتباط مابين : اولاً. (بعاد وصف الحاله البذنيه للاعبات ويعض المهارات بكرة اليا:

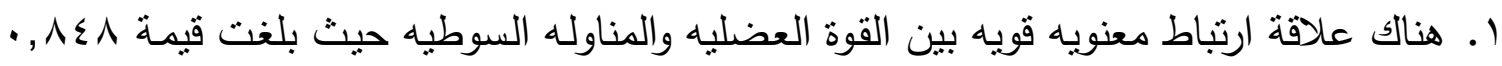

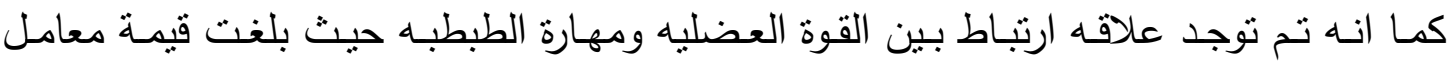
الارتباط ( إY, • --) في حين كان هناك علاقه ارتباط معنويه قويه بين القوة العضليه والتصويب بكرة اليد بلغ قيمة معامل الارتباط (سT/A, • ) مما سبق يتوضح للباحثين : ان قوة الرياضي يكون مصدرها في النظام العصبي - عضلي عن طريق تحويل الطاقه الكيمياويه او الكامنه الى طاقه حركيـه (تقلص العضله) لاداء واجب معين (مهارة) وهنـا يخضع اللاعب في كرة اليد اثتاء التدريب الى تحسين عمل العضلات المناسبة مع المهارة او الواجب الحركي ، ففي مهارة المناوله والتصويب يحتاج اللاعب الى القوة بشكل اكبر من مهارة الطبطبه ، r. وجد ان هنـاك علاقة ارتباط معنويـه قويه بين التحمل وبين المناولـه السوطيه حيث بلـغ قيمـة V • . , • في حين لم توجد علاقه معنوبه بين التحمل والطبطبه حيث بلـغ قيمة معامل الارتباط

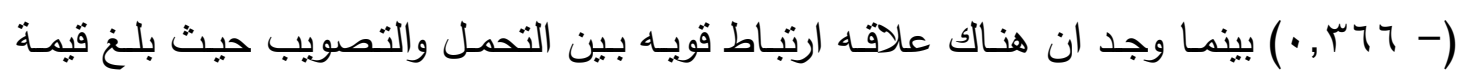
(7 19 , • ) مما سبق يتوصل الباحثون الى ان التحمل السريع ذهابا وايابا لاحراز اكبر عدد من الاهداف خلال الزمن المحدد للشوط وهنا نجد ان التحمل له علاقه وطيده للتدربب على مهارة المناوله السوطيه والتهديف لكنه يقل عند استخدام مهارة الطبطبه ويمكن ارجاع السبب هنا الى قله استخدام هذه المهارة لعدم اضاعة وقت واستغلاله للمناوله وللتهديف . r. وجد ان هناك علاقه ارتباط معنويه قويه بين السرعه ومهارة المناوله السوطيه حيث بلغت قيمته 1 A ر , · بينما لم توجد علاقه ارتباط معنويه بين السرعه ومهارة الطبطبه حيث بلغ قيمة معامل الارتباط (- وب؟ , • ) من حين وجدت هنالك علاقه ارتباط قويه بين السرعه ومهارة التصويب

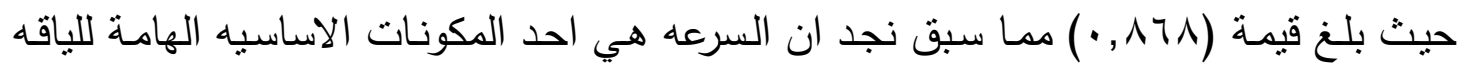

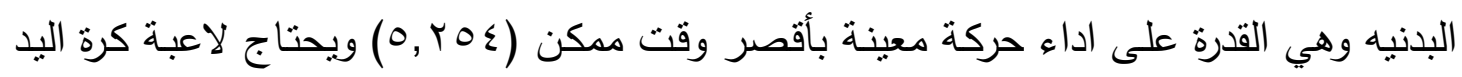
الى سرعة اداء المهارات واستغلال الوقت لاداء هجوم سريع ومنظم وهادف لذلك ظهرت العلاقه المعنويه بين السرعه والمناوله السوطيه والتصويب لان كلما قصر زمن اداء الواجب او المهارة 
كلما تمكن اللاعب من اختبار زمن رد فعل اللاعب الخصم وتمكن من اداء هجوم سريع ناجح في حين ان مهارة الطبطبه تستخدم ولكن في اغلب الاحيان للتهدئه في الملعب او عند تغير خطة

ع. وجد ان هناك عالهه ارتباط معنويه بين المرونه والمناوله حيث بلغ قيمته ( 07 ه . ) كذللك وجدت

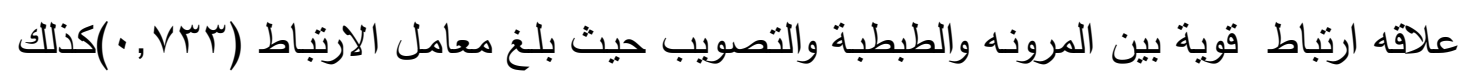

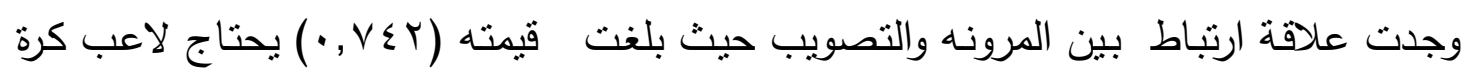

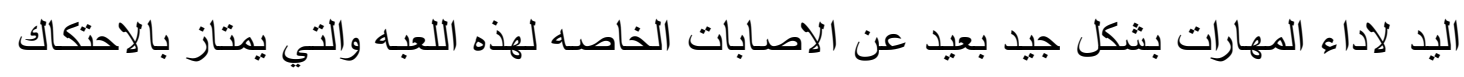

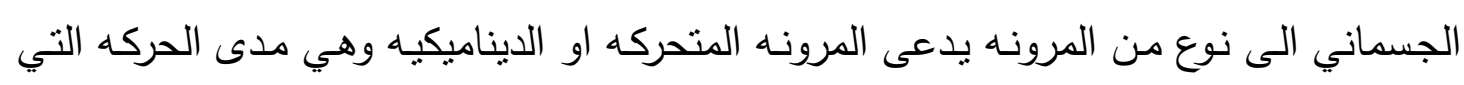

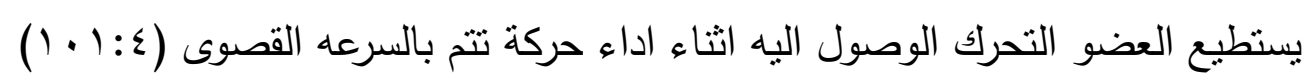

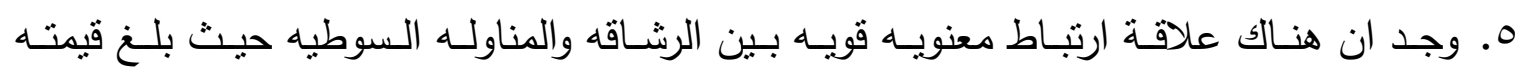

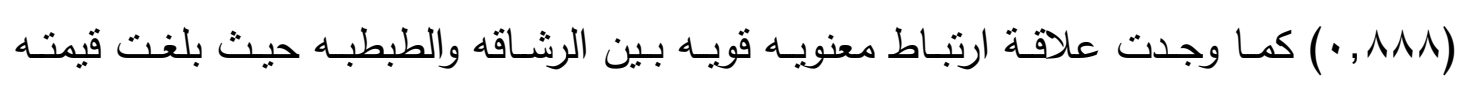

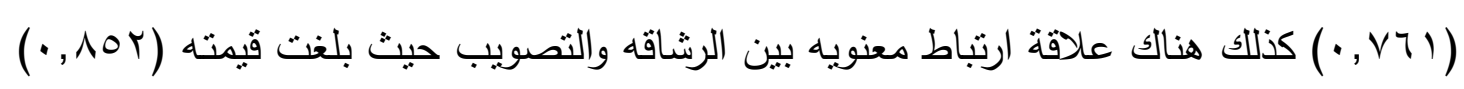

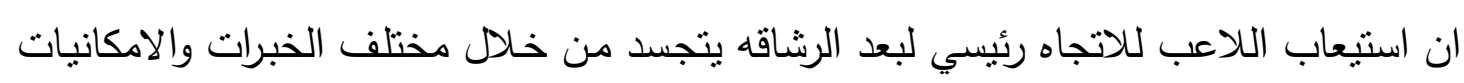

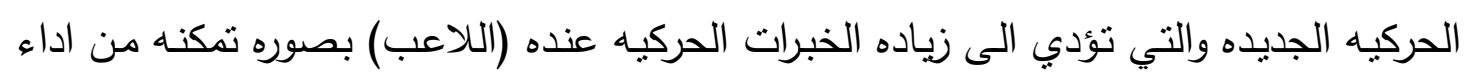
كافة المهارات بشكل انسيابي ودقيق

ثثانياً. الاتجاه نحو المنافس للاعبات ويعض المهارات بكرة اليد:

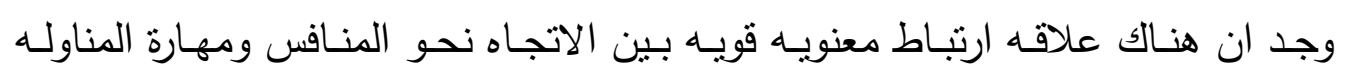

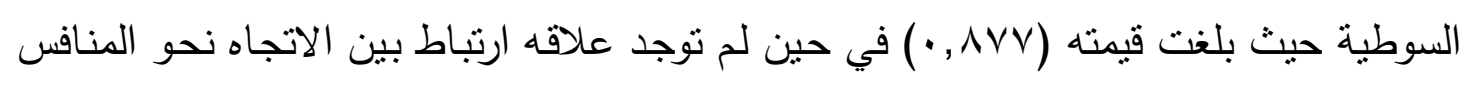

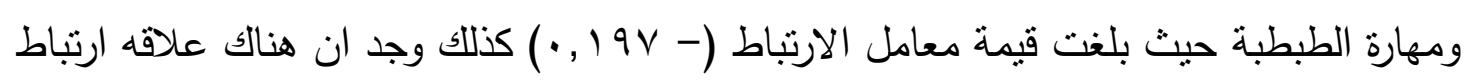

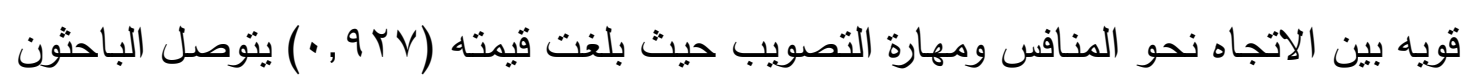

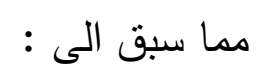

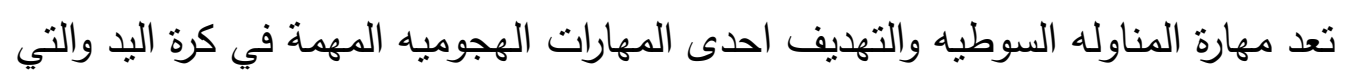
تعتمد احراز اكبر عدد من النقاط لذلك يحرص المدرب على تطوير القدرات المهاريه بحيث

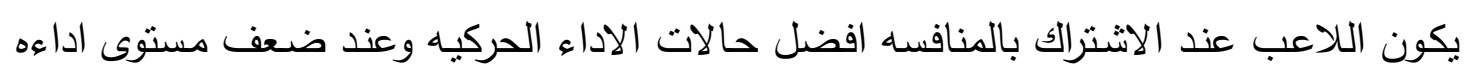

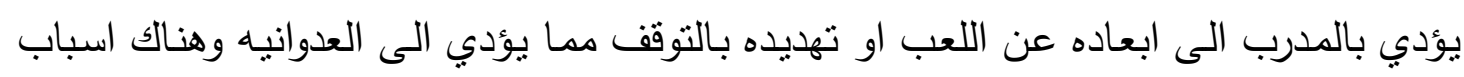

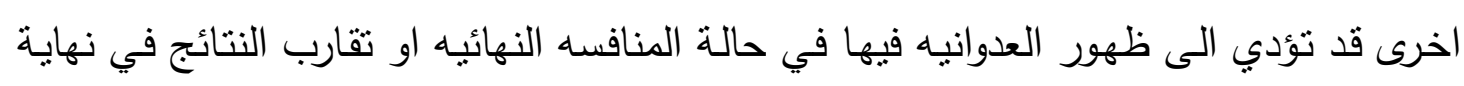
وقت المنافسه

ولتحقيق الفرضيه الثانيه نرى في الجدول رقم ((£)) 
- ان هناك علاقه ارتباط معنويه قويه بين ابعاد وصف الحاله البذنيه القوة العضليه ، التحمل،

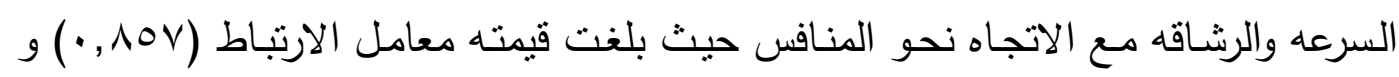

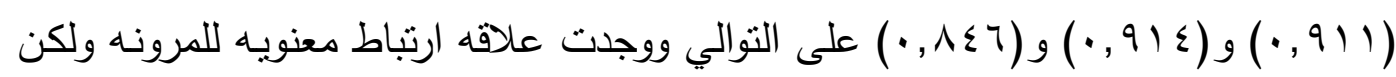

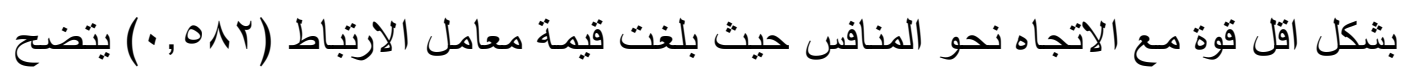

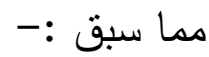
- ان هناك علاقه وثثقه بين ابعاد وصف الحاله البدنيه مع الاتجاه نحو المنافس حيث تكاد هذه العلاقه تكون متعاكسه احيانا او طرديه احيانا

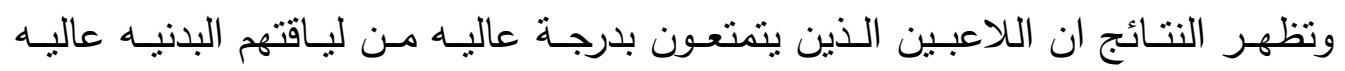

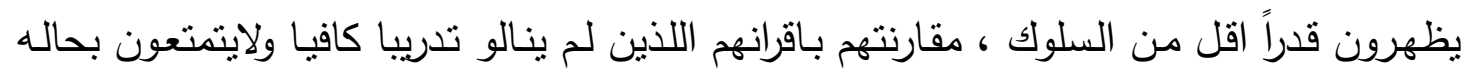

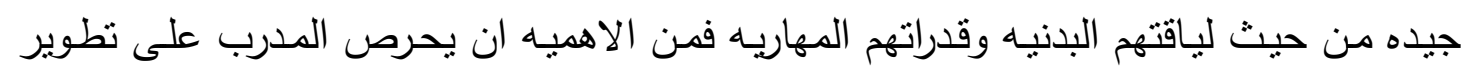

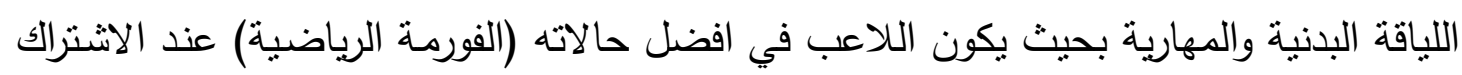

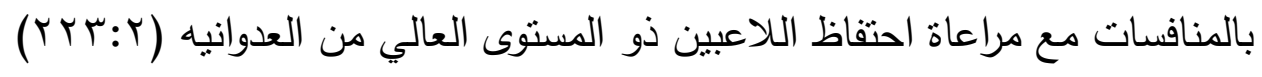
ولتحقيق الفرض الثالث نرى في الجدول (باءة

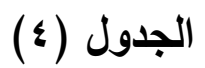

يبين تحليل الاتحدار الى المتغير المعتمد

\begin{tabular}{|c|c|c|c|c|c|}
\hline قيمة f الجدوليه & قيمة f المحسويه & متوسط المربعات & درجة الحريه & المربعات & \\
\hline 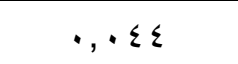 & $7, \varepsilon \vee \varepsilon$ & 7, rq9 & $\wedge$ & $01,1 Y 1$ & الانحدار \\
\hline 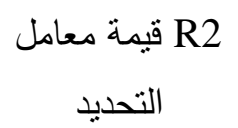 & & $\cdot, 9 \wedge \vee$ & $\varepsilon$ & $r, q \leq q$ & البواقي \\
\hline שT, & & & Ir & $00, \cdot V V$ & الكلي \\
\hline
\end{tabular}

والذي يبين تحليل تباين الانحدار الى المتغير المعتمد (مهارة المناوله السوطيه) ان قيمة

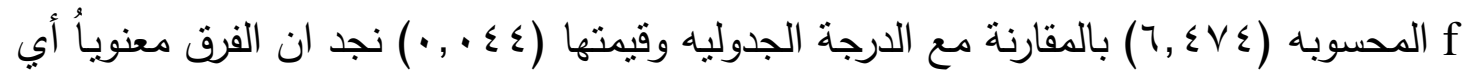

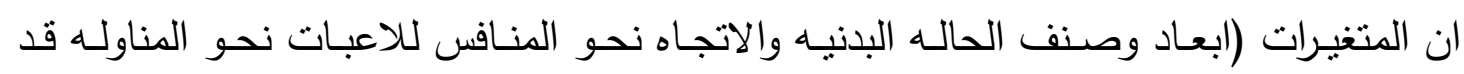

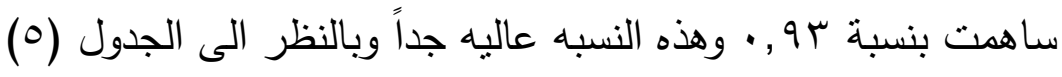




\section{الجدول (0)}

يبين تحليل تباين الانحدار الى المتغير المعتمد (المناوله السوطيه)

\begin{tabular}{|c|c|c|c|c|c|c|}
\hline \multirow{2}{*}{ النتيجه } & \multirow{2}{*}{ المعنويه } & \multirow{2}{*}{ قيمة t } & \multirow{2}{*}{ اللمعياري الخطامل } & \multicolumn{2}{|c|}{ الخطا المعياري للمعادلات } & \multirow{2}{*}{ النموذج } \\
\hline & & & & الخطيا & تقدير & \\
\hline معنوي & $\cdot, 1 \wedge$ & 1, & & IA,VY. & $r \cdot, r V V$ & الحد الثابت \\
\hline معنوي & $\cdot, \mathrm{r} \wedge \Lambda$ & . , \&MY - & $\cdot,|\lambda|$ & $\cdot, 170$ & $\cdot, \Gamma \vee \mu-$ & قوة عضليه \\
\hline معنوي &., 170 & 1,791 & $1, r \leqslant r$ & $\cdot, 7 \wedge \vee$ & $1,17 \mathrm{~V}$ & التحمل \\
\hline معنوي & $\cdot, 1 \vee 9$ & $1,7 \times 9-$ & 1,01 & $1, \sum 9 r$ & $r, \Sigma T r-$ & السرعه \\
\hline معنوي & . TYT & $1, \leqslant \Psi$. & $\cdot$ roV &., 1.9 & $\cdot, 107$ & مرونه \\
\hline معنوي & $\cdot, \leqslant 19$ & $\cdot, 019$ & $\cdot, r \leq 7$ & $\cdot .0 \vee 9$ & 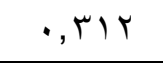 & رشاقه \\
\hline ضعيف & $\cdot, T V T$ & $\cdot, \leqslant 00-$ & $\cdot, \Pi \leq \varepsilon$ & $\cdot, 10 r$ & f-c 7,1 . & الاتجاه نحو المنافس \\
\hline
\end{tabular}

يبين الجدول رقم (0) تغذية معاملات الانحدار بين ابعاد وصف الحاله البدنيه للمتغير

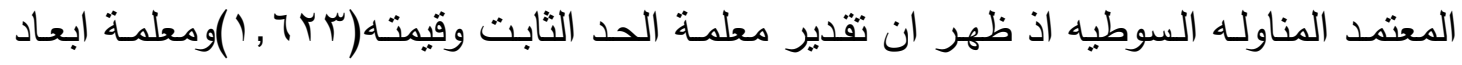

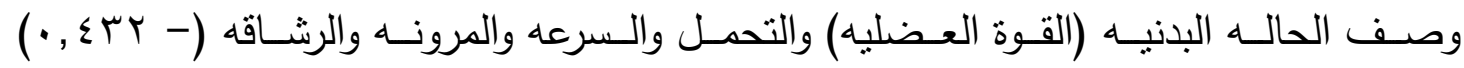

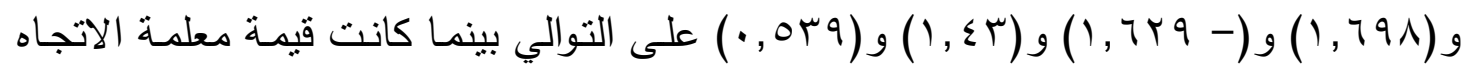

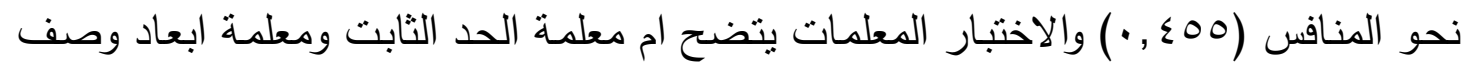
الحاله البدنيه لها تاثير معنوي على مهارة المناوله السوطيه في حين انخفضت معلمـة الاتجاه نحو المنافس لاى اللاعبات

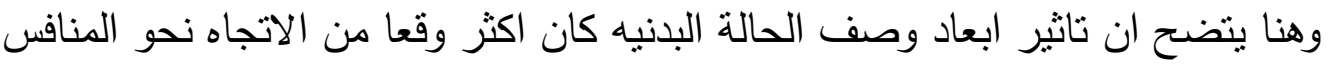
اما في الجدول رقم(T) والذي يبين تباين الانحدار الى المتغير المعتمد (مهارة الطبطبه)

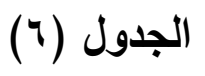

يبين تحليل الانحدار الى المتغير المعتمد (الطبطبة)

\begin{tabular}{|c|c|c|c|c|c|}
\hline قيمة f الجدوليه & قيمة f المحسويه & متوسط المربعات & درجة الحريه & المربعات & \\
\hline$\cdot, Y T$ & $\Lambda, \vee \circ 7$ & $1, \leqslant 19$ & $\wedge$ & 11, ror & الانحدار \\
\hline $\begin{array}{c}\text { R2 معامل R2 } \\
\text { التحديد }\end{array}$ & & $\cdot, 17 r$ & $\varepsilon$ & $\cdot, 7 \leqslant \Lambda$ & البواقي \\
\hline$\cdot, 9 \leq 7$ & & & ir & ${ }_{1}, \ldots$ & الكلي \\
\hline
\end{tabular}

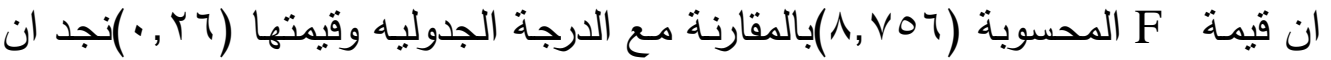
الفرق معنويـا أي ان ابعـاد وصـف الحالـه البدنيـه والاتجـاه نحو المنـافس للاعبـات نحو مهـارة الطبطبه قد ساهمت بنسبة( ب 9 , • )وهذه النسبه عاليه وبالنظر الى الجدول رقم (V) 


\section{(v) الجدول}

يبين تحليل تباين الانحدار الى المتغير المعتمد (مهارة الطبطبه)

\begin{tabular}{|c|c|c|c|c|c|c|}
\hline \multirow{2}{*}{ النتيجه } & \multirow{2}{*}{ المعنويـه } & \multirow{2}{*}{ قيمة } & \multirow{2}{*}{ للمعاري المعاري } & \multicolumn{2}{|c|}{ الخطا المعياري للمعادلات } & \multirow{2}{*}{ النموذج } \\
\hline & & & & الخطياري & المعاملات & \\
\hline معنوي & $\cdot, 1 \cdot \varepsilon$ & $r, .97$ & & $V, 010$ & 10,199 & الحد الثابت \\
\hline معنوي & $\cdot, .0 \leq$ & $r, 79$ & $\cdot, 911$ & , ro. & $\cdot, 9 \leqslant 0$ & قوة عضليه \\
\hline معنوي & $\cdot, \wedge \wedge 0$ & $1,101-$ & $\cdot, 1-$ & $\cdot, r \vee q$ & $\varepsilon, \Gamma q \varepsilon-$ & التحمل \\
\hline معنوي & $\cdot, \wedge 97$ & $r, 1 r^{\prime}$ & $\cdot, \wedge 11$ & $\cdot, r \cdot 0$ & $\Lambda, r \wedge r$ & السرعه \\
\hline معنوي & $\cdot, 74$ & Y,01V- & $\cdot, r q \mu-$ & $\cdot, \varepsilon \leqslant$ & $\cdot, 11 Y-$ & مرونه \\
\hline معنوي & •, r & $r, r \leq r-$ & $1, \lambda \cdot V-$ & $\cdot$, Yro & $\cdot$, VYI - & رشاقه \\
\hline ضعيف & $\cdot, \wedge 1$ & ., YOV - & $\cdot, 10 \leqslant-$ & $\cdot, \cdot T r$ & $1,01 .-$ & الاتجاه نحو المنافس \\
\hline
\end{tabular}

يبين الجدول رقم (V) لتقدير معاملات الانحدار بين ابعاد وصف الحاله البدنيه للمتغير المعتمد مهارة الطبطبه حيث ظهر ان تقدير معلمة الحد الثابت وقيمته) 97 . , و) ومعلمة ابعاد

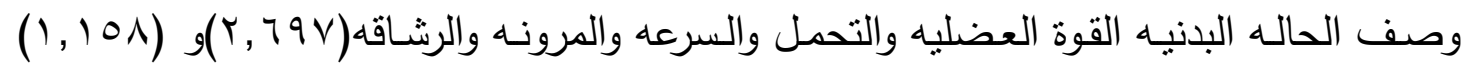

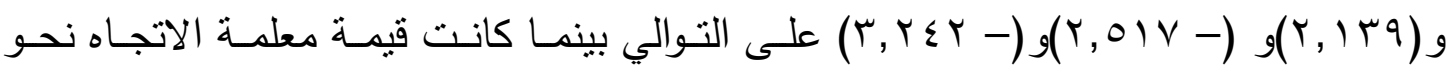

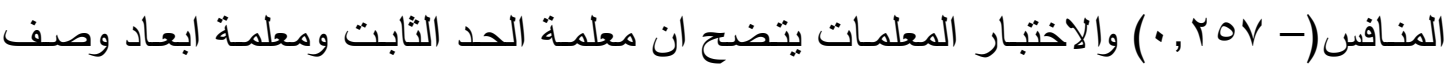

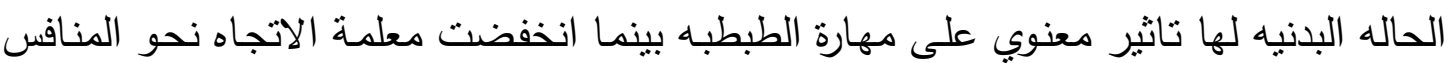
لاى اللاعبات ، وهنا يتضح ان ناثير ابعاد وصف الحاله البدنيه كان اكثر وقعا من الاتجاه نحو التهو المنافس ، اما الجدول (^) والذي يبين تحليل الانحدار الى المتغير المعتمد (التصويب) ان قيمة ولئ

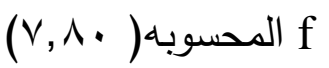

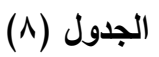

يبين تحليل الانحدار الى المتغير (التصويب)

\begin{tabular}{|c|c|c|c|c|c|}
\hline قيمة f الجدوليه & قيمة المحسويه & متوسط المربعات & درجة الحريه & المربعات & \\
\hline 更 & $\vee, \Lambda . q$ & $\varepsilon, \wedge \cdot \Lambda$ & $\wedge$ & $\lceil\wedge, \leqslant\rceil$ & الانحدار \\
\hline قيمة معامل & & $\cdot, 717$ & $\varepsilon$ & $r, \leq 7 r$ & البواقي \\
\hline$\cdot, 9 \leqslant$ & & & ir & $\varepsilon \cdot, 9 r \mu$ & الكلي \\
\hline
\end{tabular}

وبالمقارنـة مـع الدرجـة الجدوليـه(ب r, • ) نجد ان الفـرق معنويـا أي ان المتغيـرات ابعـاد وصف الحاله البدنيه والاتجاه نحو المنافس للاعبات مهارة التصويب قد ساهمت بنسبة ع 9 , . 


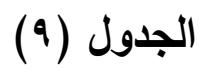

يبين تحليل تباين الانحدار الى المتغير المعتمد (التصويب)

\begin{tabular}{|c|c|c|c|c|c|c|}
\hline \multirow{2}{*}{ النتيجه } & \multirow{2}{*}{ المغنويه } & \multirow{2}{*}{ قيمة t } & \multirow{2}{*}{ اللطعا المعاري } & \multicolumn{2}{|c|}{ الخطا المعياري للمعادلات القياسيه } & \multirow{2}{*}{ النموذج } \\
\hline & & & & الخطا المعياري & تقبير المعاملات & \\
\hline معنوي & $\cdot, Y Y T$ & $1, \varepsilon \leqslant$. & & $1 \varepsilon, \vee \wedge \varepsilon$ & 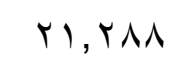 & الحد الثابت \\
\hline معنوي & •, ro. & $\begin{array}{c}- \\
1, .01\end{array}$ & $\begin{array}{c}- \\
\cdot, \varepsilon \cdot 7\end{array}$ & ת & •, VYY - & قوة عضليه \\
\hline معنوي & $\cdot, 709$ & $\cdot, T V 7$ & $\cdot, \Gamma 19$ & $\cdot, 0 \leqslant T$ & $\cdot$, rOA & التحمل \\
\hline معنوي & $\cdot, 7 \cdot 1$ & $\begin{array}{c}- \\
\cdot, 97 \mathrm{~V}\end{array}$ & $\begin{array}{c}- \\
\cdot,, \leqslant \wedge)\end{array}$ & $1,1 \vee 9$ & $\cdot, 741-$ & السرعه - الس \\
\hline معنوي & $\cdot, r \leqslant \vee$ & $\begin{array}{c}- \\
1, .70\end{array}$ & $\begin{array}{c}- \\
\cdot, \mid, 74\end{array}$ & $\cdot, \cdot 14$ & $9,19 v-$ & مرونه \\
\hline معنوي & $\cdot, r 01$ & $1, .0 \leqslant$ & $\cdot, \pi r$. & $\cdot, \leqslant \circ \mathrm{V}$ & - \&AY & ر تشاقه \\
\hline ضعيف & $\cdot, \wedge 9$. & $\begin{array}{l}- \\
., 1 \leq V\end{array}$ & $\begin{array}{c}- \\
\cdot, .9 r\end{array}$ & $\cdot, \mid r$. & 1,V74 - & الاتجاه نحو المنافس \\
\hline
\end{tabular}

اما من خلال جدول رقم (9) لتقدير معاملات الانحدار بين ابعاد وصف الحاله البدنيه

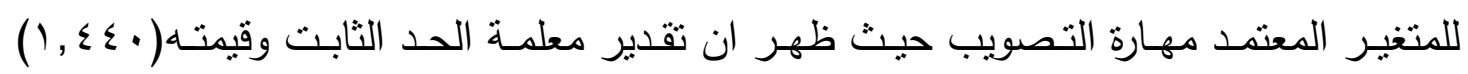
ومعلمـة ابعـاد وصـف الحالـة البدنيـهـ (القـوة العضليه والتحهـل والـسرعه والمرونسه والرشـاقه)

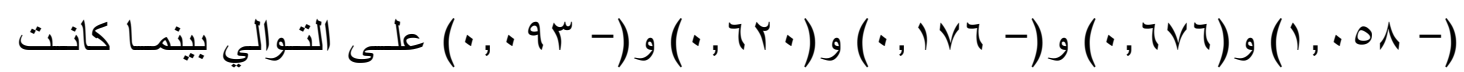
قيمة معلمة الاتجاه نحو المنافس (- (

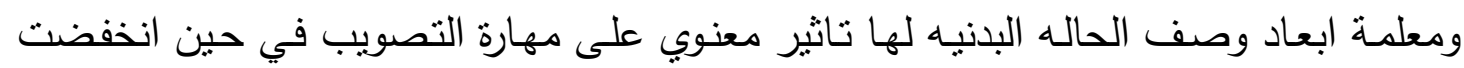

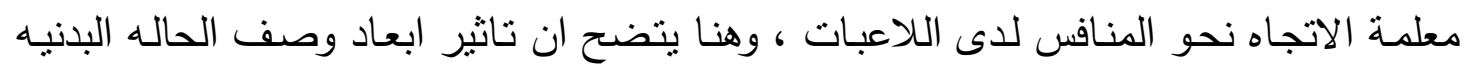

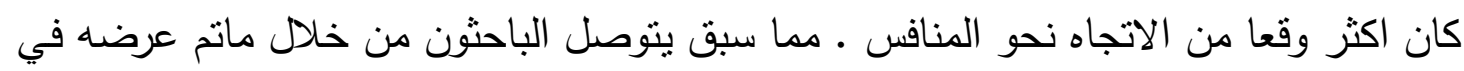

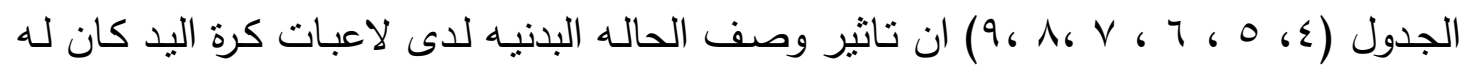

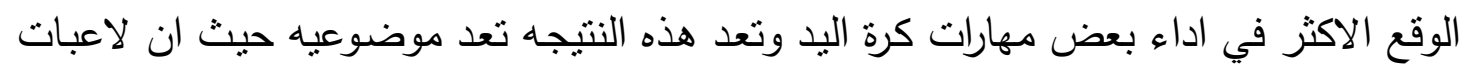

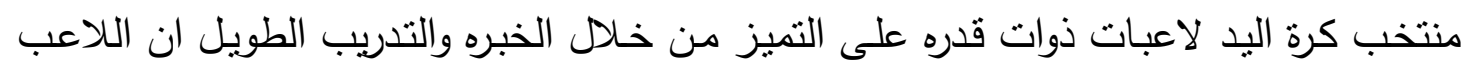

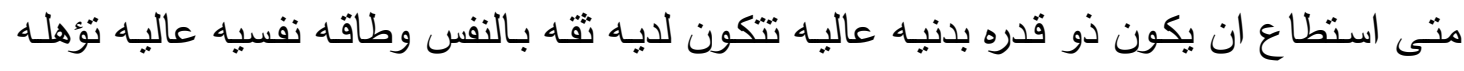

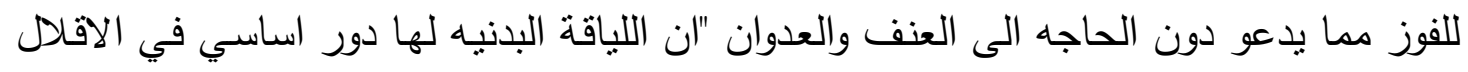
من السلوك العدواني وزيادة الضبط الانفعالي لذا يجب ان يحظي جميع اللاعبين بقدر كبير من الن النيان

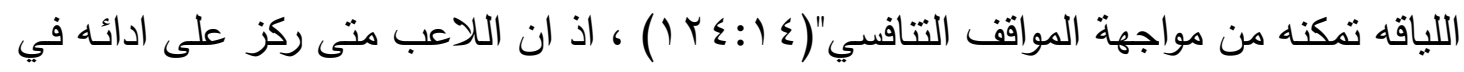

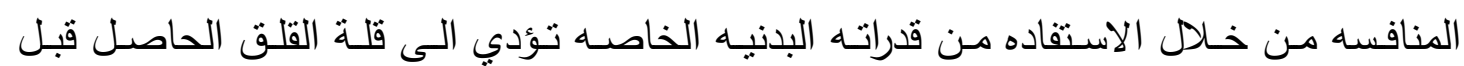


المنافسه والتي تؤدي في حالة عدم السيطرة عليه الى التوتر الزائد الذي ينصب في اصـابته

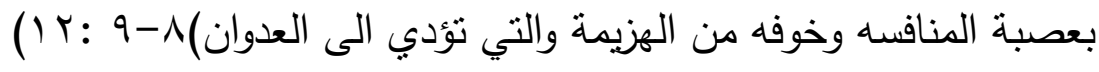

$$
\begin{aligned}
& \text { 0ـ الاستنتاجات و التوصيات : } \\
& \text { 0- } 1 \text { الاستتناجات: } \\
& \text { توصل الباحثون الى ما يأتي: }
\end{aligned}
$$

ا ـ وجد هناك علاقه قويـة بين ابعاد وصف الحالة البدنيه (القوة العضليه والتحمل والسرعه

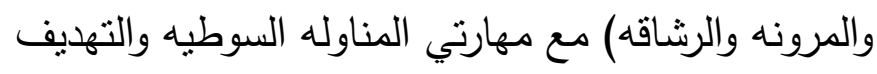

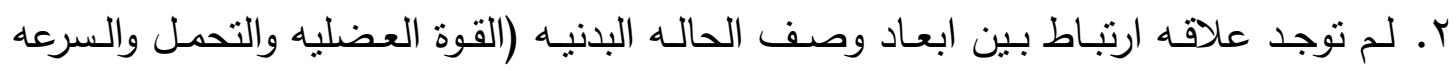
والمرونه مع مهارة الطبطبه)

r. وجدت علاقهارتباط بين كل من الرشاقه والمرونه وبين الطبطبه

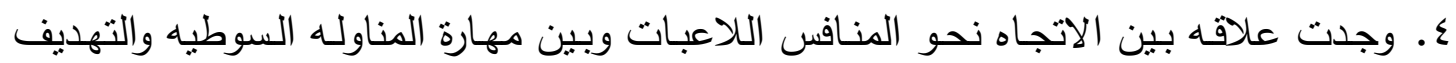

$$
\text { والطبطبه }
$$

ه. ان تاثير ابعاد وصف البدنيه اللاعبات كرة اليد كان اقوى من الاتجاه نحو المنافس بالنسبه لاداء المهارات المناوله السوطيه والطبطبه والتهديف

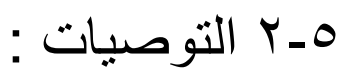

يوصي الباحثون بما يأني:

ا ـ ضرورة الاهتمام ابعاد وصف الحالة البدينه للاعب اووضحة باني ضمن البرنامج التدريبي لزيادة

$$
\text { كفاءة الذات لدية }
$$

r. الاهتمام بتطوير عنصر الرشاقة والمرونه بصورة اكثرلمالها من اهمية في المهارات الهجومية r. التاكيد على الحفاظ على مستوى معين من اتجاه اللاعب نحو المنافس للتقليل من السلوك الغير رياضي وانجازهم عن قوابنين اللعبه 
I I ابراهيم ريكان: النفس والعدوان ، بغداد ، دار الثؤون الثقافيه ،

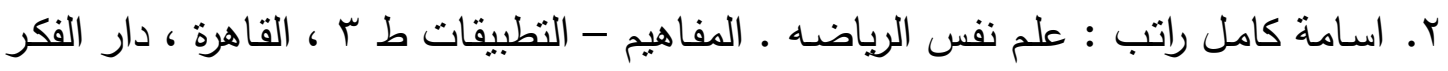

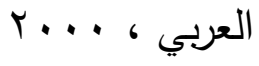

r. تريفرز : علم النفس التربوي (ترجمة) موفق الحمداني ومحمد ولي الكربولي، بغداد ، مطبعة

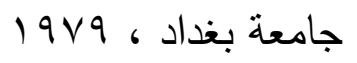

ـ. حلمي حسين: الياقه البدنيه ، قطر ، دار المتنبي، 1910 ه. ريسان خريبط محمد : التدريب الرياضـي ، البصرة، مديريـة دار الكتب للطباعـة والنشر

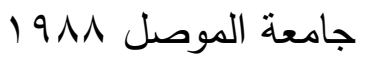

7. ضياء الخياط، عبد الكريم غزال ـ كرة اليد ـ الموصل. دار الكتب للطباعة والنشر ، 1911

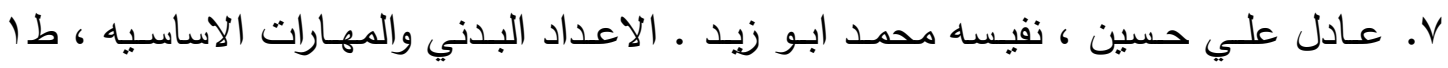

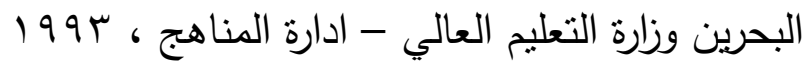

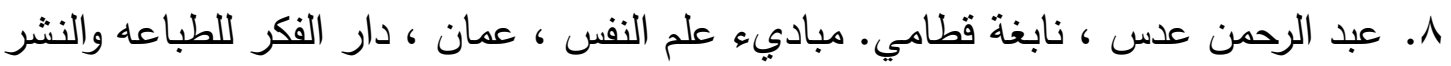

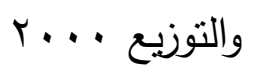

9 9. علي كمال ـ النفس وانفعالاتها ، جr ، العراق، دار واسط 1919

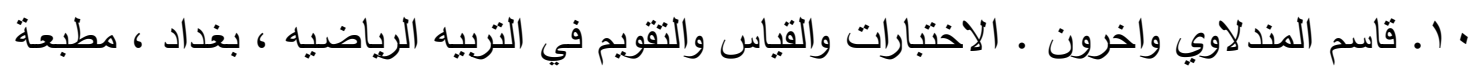

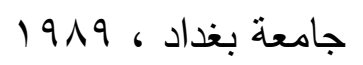

1 ا ـ محمد حسن عـاوي موسوعه الاختبارات النفسيه للرياضيين ، القاهرة ، مركز الكتاب 1991 للنشر

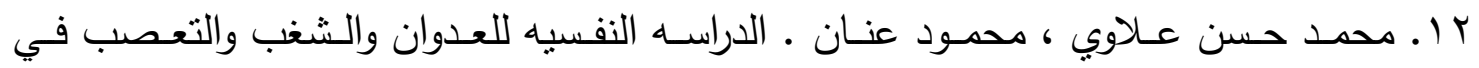

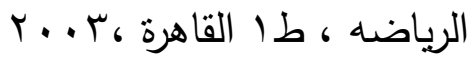

با ـ محمد نصر الدين رضوان ـ الاحصاء الاستخلالي في علوم التربيه البدنيه والرياضه ، طا طا ،

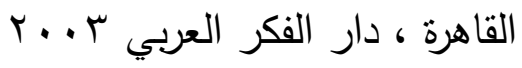

ع (. محمود عبد الفتاح عنان، سيكلوجية المنافسات الرياضبه ، مركز المعلومات والتوثيق ادارة النشر 199 199

1 ـ مصطفى حسين باهي ، سمير عبد القادر ـ المدخل الى الاتجاهات الحديثه في علم النفس

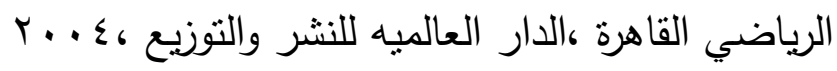

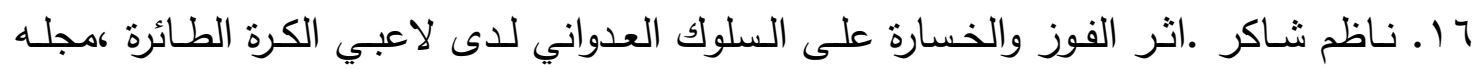
الرافدين للعلوم الرياضيه ، العدد ب ، جامعة الموصل ، 1990 . 


\section{الملحق (1)}

\begin{tabular}{|c|c|c|c|c|c|}
\hline \multicolumn{6}{|c|}{ تطبق على بدرجة جدا =0 بدرجة كبيرة =ع بدرجة منوسطة = r بدرجة قليلة = بدرجة قليلة جدا = } \\
\hline 0 & $\xi$ & $r$ & $r$ & 1 & 1- اشعر بالضعف في بعض عضلات جسمي \\
\hline 0 & $\varepsilon$ & $r$ & $r$ & 1 & r- استطيع ان اعود لحالتي الطبيعية بسرعة بعد اداء مجهود بدني عنيف \\
\hline 0 & $\varepsilon$ & $r$ & $r$ & 1 & r- معظم زملائي اسرع مني في الجرى \\
\hline 0 & $\varepsilon$ & $r$ & $r$ & 1 & ع - استطيع جيدا اداء الحركات التي تتطلب درجة كبيرة من مرونه الجسم \\
\hline 0 & $\varepsilon$ & $r$ & r & 1 & 0- لاستطيع بسهوله اداء الحركات التي تتطلب الرشاقة \\
\hline$\circ$ & $\varepsilon$ & $r$ & r & 1 & ؟- استطيع حمل الاثتياء التقيلة بسهوله \\
\hline 0 & $\varepsilon$ & $r$ & r & 1 & V - اتعب بسرعة عند بذل جهد بدني لفترة طويله \\
\hline 0 & $\varepsilon$ & $r$ & r & 1 & 1- اجيد اداء الحركات التي تتطلب السرعة \\
\hline 0 & $\varepsilon$ & $r$ & r & 1 & 9- مرونه جسمى لاتساعدني على اداء معظم الحركات بصورة جيدة \\
\hline 0 & $\varepsilon$ & $r$ & r & 1 & • 1- استطيع بسهولة تغيير اوضاع جسمى عند اداء بعض المهارات الحركية \\
\hline 0 & $\varepsilon$ & $r$ & r & 1 & 11 - حسمى ليس قويا بدرجة كافية \\
\hline 0 & $\varepsilon$ & $r$ & r & 1 & r ا - استطيع اداء مجهود بدني عنيف دون ان اتوقف لالتقط انفاس \\
\hline 0 & $\varepsilon$ & $r$ & r & 1 & س ا - احتاج الى تتمية قدراتي في الجرى السريع (العدو) \\
\hline 0 & $\varepsilon$ & $r$ & r & 1 & ع ا - بعض زملائى يصفونني بان جسمى يتميز بالمرونه الجيدة \\
\hline \multicolumn{6}{|c|}{ تتطبق على بدرجة جدا =0 بدرجة كبيرة = ع بدرجة منوسطة = r بدرجة قليلة = ب بدرجة قليلة جدا = } \\
\hline 0 & $\varepsilon$ & r & r & 1 & 1 1 - انا ضعيف في اداء الحركات التي تتطلب الرشاقة \\
\hline 0 & $\varepsilon$ & $r$ & r & 1 & 1 1 - معظم زملائى يصفونني باننى قوى بدينا \\
\hline 0 & $\varepsilon$ & r & r & 1 & V - لاستطيع تحمل الاداء البدني المتواصل بدون فترة راحة طويله \\
\hline 0 & $\varepsilon$ & r & r & 1 & 1 1 - قدراتى جيدة في الانشطة التي تتطلب سرعة الحركة \\
\hline 0 & $\varepsilon$ & $r$ & r & 1 & 9 1 - اثُعر بان جسمى ليس مرنا بدرجة كافية \\
\hline 0 & $\varepsilon$ & $r$ & r & 1 & • ץ- معظم زملائي يصفوننى باننى اجيد الحركات التي تتطلب درجة كبيرة من الرشاقة \\
\hline 0 & $\varepsilon$ & r & r & 1 & اب - عضلات جسمى لاتظهر بصورة واضحة \\
\hline 0 & $\varepsilon$ & r & r & 1 & r Y- بعض زملائى يصفوننى باننى لاتعب بسرعة اثثاء ممارسة بعض الانشطة الرياضية \\
\hline 0 & $\varepsilon$ & $r$ & $r$ & 1 & rץ- لاسيطيع اداء بعض الحركات التي تتطلب السرعة في الاداء \\
\hline 0 & $\varepsilon$ & $r$ & r & 1 & ؟ ؟- - لااسيطيع بالرضا من ناحية مرونه جسمى \\
\hline ० & $\varepsilon$ & r & r & 1 & هץ- لاسيطيع بسهوله تغيير اتجاهات جسمى عند اداء بعض المهارات الحركية \\
\hline 0 & $\varepsilon$ & $r$ & r & 1 & جr- اشعر بالقوة في معظم عضلات جسمى \\
\hline 0 & $\varepsilon$ & $r$ & $r$ & 1 & PV - - اشعر لوقت طويل حتى استرد انفاس عقب بذلى لمجهود بدنى عنيف \\
\hline 0 & $\varepsilon$ & $r$ & r & 1 & ^ץ- انا اسرع من معظم زملائى في الجرى \\
\hline 0 & $\varepsilon$ & $r$ & r & 1 & وץ- لاستطيع بسهوله اداء الحركات التي تتطلب درجة كبيرة من مرونه الجسم \\
\hline 0 & $\varepsilon$ & r & r & 1 & • r- استطيع بسهوله اداء الحركات التي تتطلب الرشاقة \\
\hline
\end{tabular}




\section{الملحق (r)}

مقياس الاتجاه نحو المنافس

\begin{tabular}{|c|c|c|c|c|c|}
\hline ابدا & نادرا & احيانا & غالبا & دائما & 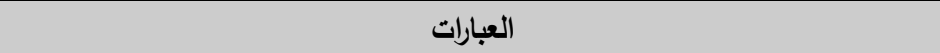 \\
\hline \multirow[t]{2}{*}{1} & r & r & $\varepsilon$ & ○ & ا ـ يغلب على لعبى طابع الخشونه والعنف عندما يحاول البعض استفزازى \\
\hline & & & & & r.اثثاء المنافسة لاشتعر باى رغبة في ايذاء منافس . \\
\hline 1 & r & r & $\varepsilon$ & 0 & r. لكى يفوز اللاعب لابد له ان يهاجم منافسه بعنف خشونه \\
\hline \multirow[t]{2}{*}{1} & r & r & $\varepsilon$ & 0 & ع. اثناء المنافسه اشعر باننى اصبحت شخصا اخر اكثر عنفا مما \\
\hline & & & & & هـ اذا استخدم منافس الخشونه والعنف معى فاننى احاول تجنبة \\
\hline \multirow[t]{2}{*}{1} & r & r & $\varepsilon$ & 0 & 7. احاول استخدام اللعب لاهارب منافس \\
\hline & & & & & V. عندما توقيع هزيمنى فاننى العب بخشونه وعنف \\
\hline \multirow[t]{2}{*}{1} & r & r & $\varepsilon$ & 0 & ^ـ. اعتقد انه لايوجد سبب معقول اللاعتداء عمى اى لاعب منافس \\
\hline & & & & & 9. بعض الزملاء يصفوننى لاعب عنيف جدا في لعبى \\
\hline 1 & r & r & $\varepsilon$ & 0 & • 1. في بعض المواقف اشعر برغبة في ايذاء منافس \\
\hline \multirow[t]{2}{*}{1} & r & r & $\varepsilon$ & 0 & بالاعتداء علية شعرت بنية لاعب منافس في الاعتداء على فاننى ابادر \\
\hline & & & & & r ا ـ لاستخدم العنف البدني اثثاء اشتراكي في المنافسة \\
\hline \multirow[t]{2}{*}{1} & r & r & $\varepsilon$ & 0 & r ا ـ اجد نفس مضطرا لاستخدام العنف عندما يحاصرنى منافس \\
\hline & & & & & ع ا ـ يضايقنى ان مدربى لايقبل طريق لعبى التي تتميز بعدم الخشونه \\
\hline 1 & r & r & $\varepsilon$ & 0 & 1 1 ـ المنافسة الرياضية كالحرب تحتاج الى الهجوم العنيف الذي يتميز \\
\hline 1 & r & $r$ & $\varepsilon$ & 0 & 17 ا ـ بعض الزملاء يصفوننى باننى لاعب مسالم في لعبى \\
\hline 1 & r & r & $\varepsilon$ & 0 & الذي يحاول استفزازى او مضايقتى قادى على التحمى في اندفاعى نحو ايذاء منافس \\
\hline 1 & r & r & $\varepsilon$ & 0 & 11 اصـ عندما يصيب منافس احد وملائى فاننى انتقم لزميلى بان احاول \\
\hline \multirow[t]{2}{*}{1} & r & r & $\varepsilon$ & 0 & 19 1. عندما اصاب بالاحباط اثثاء المنافسه فاننى لاحاول ان العب \\
\hline & & & & & •r. احب ان اكون عنيفا في لبعى لكى يخشانى منافس \\
\hline 1 & r & r & $\varepsilon$ & 0 & آ است. عندما يقوم البعض باستفزازى اثثاء المنافسة فاننى لاميل الى معنه \\
\hline 1 & r & r & $\varepsilon$ & 0 & 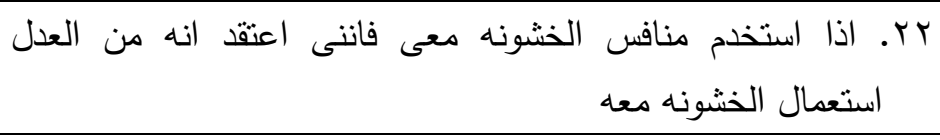 \\
\hline 1 & r & r & $\varepsilon$ & $\circ$ & rr. اذا حاول منافس اصابتى اثثاء اللعب فاننى احاول اصابته \\
\hline 1 & r & $r$ & $\varepsilon$ & 0 & ع ז. لاحاول استخدام العنف لاهارب منافس \\
\hline
\end{tabular}

